\title{
Clinical Ethics Support for Healthcare Personnel: An Integrative Literature Review
}

\author{
Dara Rasoal $^{1} \cdot$ Kirsti Skovdahl $^{2} \cdot$ Mervyn Gifford $^{1}$ • \\ Annica Kihlgren ${ }^{1}$
}

(C) The Author(s) 2017. This article is an open access publication

\begin{abstract}
This study describes which clinical ethics approaches are available to support healthcare personnel in clinical practice in terms of their construction, functions and goals. Healthcare personnel frequently face ethically difficult situations in the course of their work and these issues cover a wide range of areas from prenatal care to end-of-life care. Although various forms of clinical ethics support have been developed, to our knowledge there is a lack of review studies describing which ethics support approaches are available, how they are constructed and their goals in supporting healthcare personnel in clinical practice. This study engages in an integrative literature review. We searched for peer-reviewed academic articles written in English between 2000 and 2016 using specific Mesh terms and manual keywords in CINAHL, MEDLINE and Psych INFO databases. In total, 54 articles worldwide described clinical ethics support approaches that include clinical ethics consultation, clinical ethics committees, moral case deliberation, ethics rounds, ethics discussion groups, and ethics reflection groups. Clinical ethics consultation and clinical ethics committees have various roles and functions in different countries. They can provide healthcare personnel with advice and recommendations regarding the best course of action. Moral case deliberation, ethics rounds, ethics discussion groups and ethics reflection groups support the idea that group reflection increases insight into ethical issues. Clinical ethics support in the form of a "bottom-up" perspective might give healthcare personnel opportunities to think and reflect more than a "top-down" perspective. A "bottom-up" approach leaves the healthcare personnel with the moral responsibility for their choice of action in
\end{abstract}

\section{Dara Rasoal}

dara.rasoal@oru.se

1 School of Health and Medical Sciences, Örebro University, Fakultetsgatan 1, SE - 70182 Örebro, Sweden

2 Department of Nursing and Health Sciences, University College in Southeast Norway, Drammen, Norway 
clinical practice, while a "top-down" approach risks removing such moral responsibility.

Keywords Ethics $\cdot$ Health personnel $\cdot$ Moral case deliberation · Ethics consultation $\cdot$ Ethics committees $\cdot$ Ethics rounds $\cdot$ Ethical reflection

\section{Introduction}

Healthcare personnel frequently face ethically difficult situations in the course of their work and these issues cover a wide range of areas in clinical practice (Astrom et al. 1995; Beauchamp and Childress 2009; Lindseth et al. 1994; Sørlie et al. 2000; Tabitha et al. 1979) and community home healthcare services (Karlsson et al. 2013). In such situations, healthcare personnel can experience unease or uncertainty (Cohen and Erickson 2006) over what is right or good to do, or there may be disagreement about what should be done. Moreover, some ethical issues can be connected to conflicting interests between healthcare workers and patients and their next-of kin (Beauchamp and Childress 2009; Rasoal et al. 2015); for example, situations where patients do not follow the recommendations of healthcare personnel, such as when patients and healthcare personnel have different opinions regarding what to do (Hermsen and van der Donk 2009; Slettebø and Bunch 2004), or issues that are related to ongoing life-sustaining treatment (Cassel 1984; Schaffer 2007; Silén et al. 2008). At times, healthcare personnel experience distress as a result of ethical issues in patient care (Kälvemark et al. 2004; Pauly et al. 2009).

One way to support healthcare personnel in dealing with these ethical challenges has been through the development of clinical ethics support (CES). CES is defined as the formal or informal provision of advice and support to healthcare personnel on ethical issues arising from clinical practice and patient care within the healthcare setting (Owen 2001; Puntillo et al. 2001; Slowther et al. 2004a). CES is becoming more prevalent with the increased awareness worldwide of the importance of ethical issues in healthcare and with personnel encountering an increasing number of ethical issues in clinical practice (Bartholdson et al. 2015; Doran et al. 2015; Oberle and Hughes 2001; Ulrich et al. 2010).

Philosophical papers and empirical research have led to the development of various approaches to CES that have the goal of supporting healthcare institutions, healthcare personnel, and patients as well as next-of-kin ( $⿱$ Astrom et al. 1995; Reiter-Theil and Hiddeman 2000). There are no universal norms regarding which approaches should be used to support healthcare personnel in clinical practice. CES approaches can roughly be divided into "top-down" or "bottom-up" perspectives, which can be contrasted in terms of the nature, purpose and goals of the support. Within "top-down" perspectives, an ethical consultant or a group of "experts" has an influential advisory role or act(s) as the primary ethical decision maker, providing advice or recommendations (Aulisio et al. 1998; Crigger 1995; La Puma and Schiedermayer 1991). Those supporting such an approach claim that the ethical issues in healthcare are too complex to be managed by the healthcare personnel 
themselves. In this vein, personnel facing ethical issues require specialist expertise in the same way that medical doctors need to consult with each other within different specialties (La Puma and Schiedermayer 1991). In contrast, in "bottomup" approaches to CES, reflection begins with healthcare personnel's everyday experiences of ethical issues in clinical practice (Hansson 2002). The discussion is facilitated by an ethicist or philosopher, a "facilitator" who has the goal of fostering greater insight among the personnel into ethical considerations rather than focusing on decision-making in any particular case (Hansson 2002; Stolper et al. 2014). Adherents of "bottom up" approaches claim that ethical issues need to be reflected on critically by the healthcare personnel themselves, since they are the only legitimate decision-makers and are morally responsible for the outcomes (Hansson 2002). The facilitator for such an approach is considered to lack the knowledge needed to give advice and make recommendations for the best course of action. The existence of such contrasting approaches leaves the question open regarding which approach can be "the golden middle way" to guide healthcare personnel in clinical practice.

However, to our knowledge, there is a lack of integrative reviews regarding available approaches to ethics support and how different approaches support healthcare personnel deal with ethical issues. It is reasonable to believe that practitioners need some kind of CES reflection that relates to their personal experiences of everyday ethical issues. Therefore, in this paper, we aim to describe which clinical ethics support approaches are available to support healthcare personnel in clinical practice in terms of their construction, functions and goals.

\section{Method}

\section{Design}

This integrative literature review applies a descriptive design using the matrix method (see Garrard 2010).

\section{Search Strategy}

\section{Systematic Search}

Electronic databases of CINAHL, MEDLINE and Psych INFO were systematically used to search for relevant peer-reviewed articles. This literature review process was begun by first identifying specific search terms (i.e., indexed search terms) thorough Cinahl headings, Mesh and Thesaurus. A list of possible search terms that could be relevant for the study aim was created. In the database Psych INFO, we used the following suggested search terms: "ethics" AND "health personnel"; in CINAHL, the headings "ethics" OR "ethics committees" AND "health personnel"; in MEDLINE, the Mesh terms "ethics" OR "ethics committees" OR "ethics consultation" OR "clinical ethics" OR "institutional ethics" AND "health personnel" were used. 


\section{Manual Search}

The expertise of two experienced librarians from the university and the university hospital independently assisted in the search for relevant articles together with the first author. The two manual searches conducted in the database Summon used the following search terms: "clinical ethics support" and "ethics support". A more detailed description of the search strategy is provided in Fig. 1.

\section{Inclusion and Exclusion Criteria}

The selected articles consisted of: (1) empirical studies or theoretical papers, (2) that reflected on ethical issues in health care, (3) and that wrote about established ethics support approaches aimed at supporting healthcare personnel in clinical practice. Articles were excluded if they concerned approaches that only focused on patients and families, research design issues, policy, education, biogenetic research, pharmaceutical studies, or research on animals. Editorials and review articles were also excluded.

\section{Search Outcome}

\section{Systematic Search}

The systematic search in Psych INFO yielded 141 articles, in CINAHL 248 articles and in MEDLINE 320 articles (Fig. 1). Limiting the search to English-language peer-reviewed journals published in 2000-2016, reduced the total number of articles

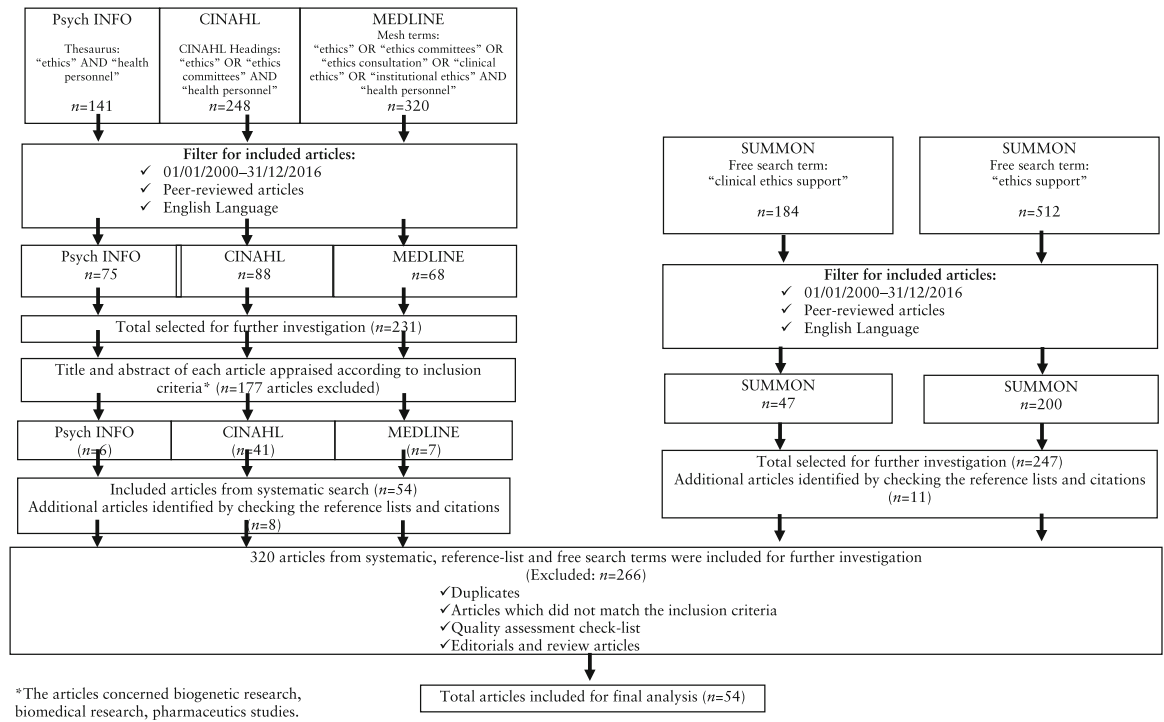

Fig. 1 Overview flowchart regarding the search steps and inclusion process 
from the three databases to 231 articles. The titles, and when available the abstracts, were scrutinized by the authors in relation to the inclusion criteria, which resulted in the exclusion of 177 articles and the selection of 54 articles for further investigation. From the systematic search of all three databases, 54 articles were selected for further investigation. After checking the reference lists of the articles and citations, eight additional articles were found.

\section{Manual Search}

The first manual search using the search term "clinical ethics support" yielded 184 articles. The second manual search using the search term "ethics support" found 512 articles. After applying the inclusion criteria of English-language peer-reviewed articles, published in 2000-2016, the number of articles reduced to 247. Checking the reference lists and citations revealed 11 additional articles.

\section{Quality Appraisal}

In total, 320 articles from the systematic and manual searches, as well as additional articles that were identified by checking the reference lists and citations, were included for further investigation. Three of the authors read and appraised the articles by reading the titles, and when available the abstracts. We excluded duplicates, articles that did not match the inclusion criteria, editorials and review articles. After the appraisal of the 320 articles, 54 remained for further analysis. Full text was not available for three of the articles, and they had to be purchased. All the articles were discussed among all of the authors in order to reach agreement regarding the content in relation to the research aim. We used a quality assessment check of the included articles (SBU 2014). The included articles were both theoretical papers and empirical research that reflected on ethically difficult situations in health care and how to support health personnel from diverse cultures and countries worldwide.

\section{Data Analysis}

Empirical, qualitative and quantitative studies as well as theoretical papers with various approaches were included. First, the articles were sorted based on the CES approach. Second, a critical review of each article was performed, with particular attention given to the results and conclusions and their relation to the aim provided in the article. Notes were made regarding their content (Table 1). The analysis process was inspired by manifest content analysis (Graneheim and Lundman 2004).Third, the important parts of each article, such as approach, aim, method, results and conclusion, were written up into a matrix (Garrard 2010). Fourth, the results and conclusions of each qualitative, quantitative and theoretical paper were imported into to a new sheet in a word processor so they could be coded. Fifth, the first author performed descriptive coding of the articles' results and conclusions. Sixth, based on content similarities and differences among the similar approaches, descriptive and manifest categories emerged from the codes. Finally, the results of 


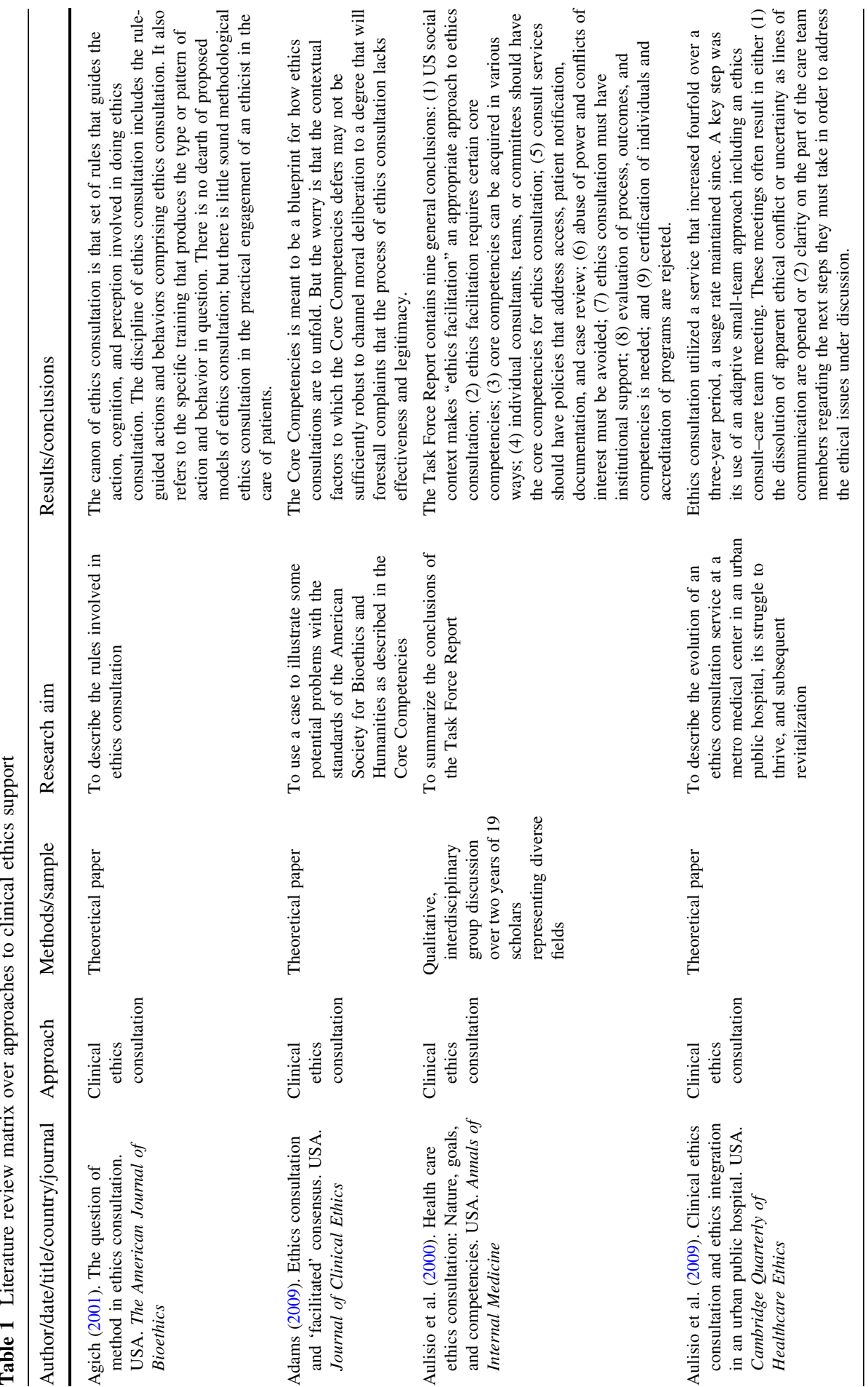




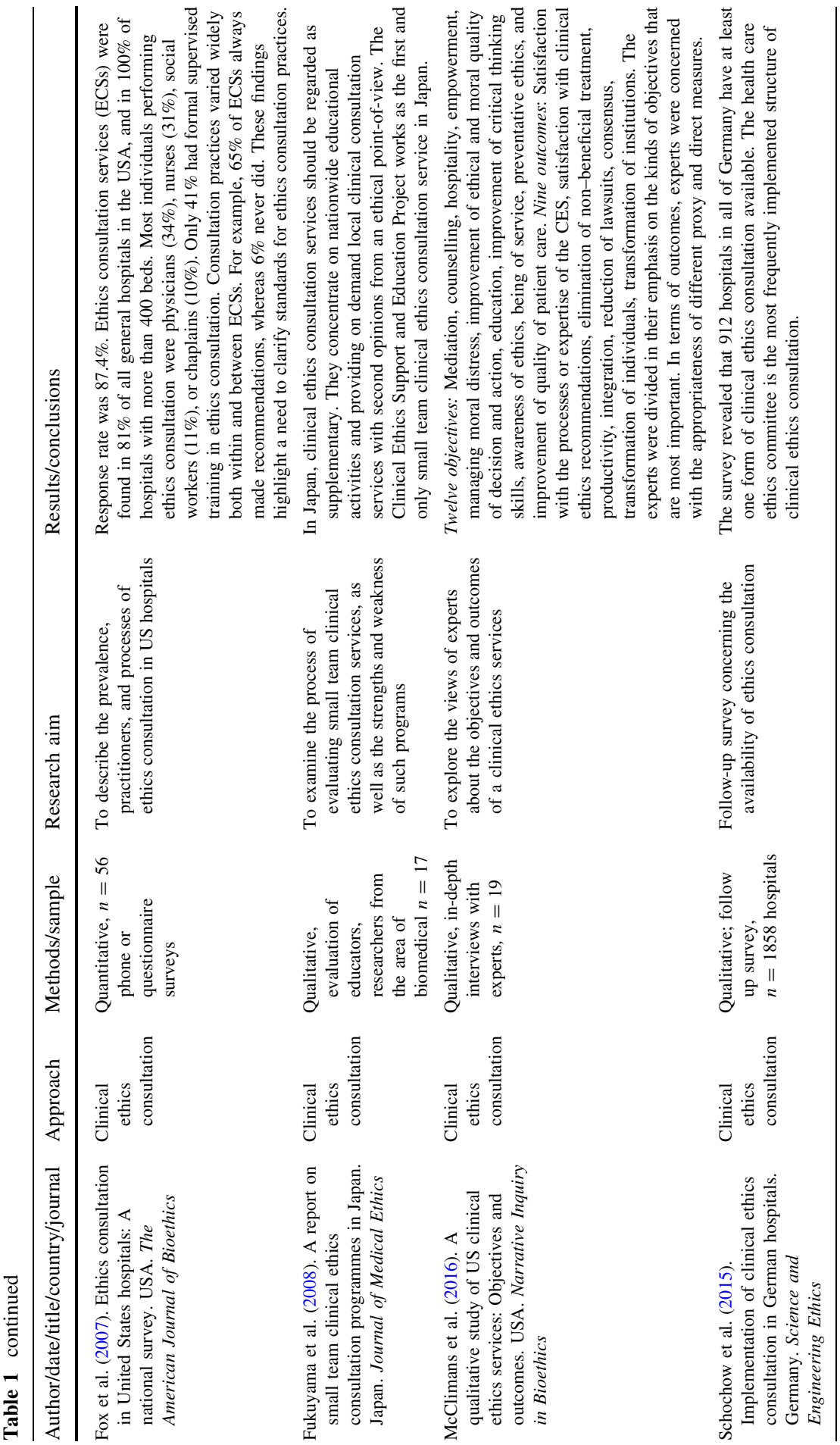




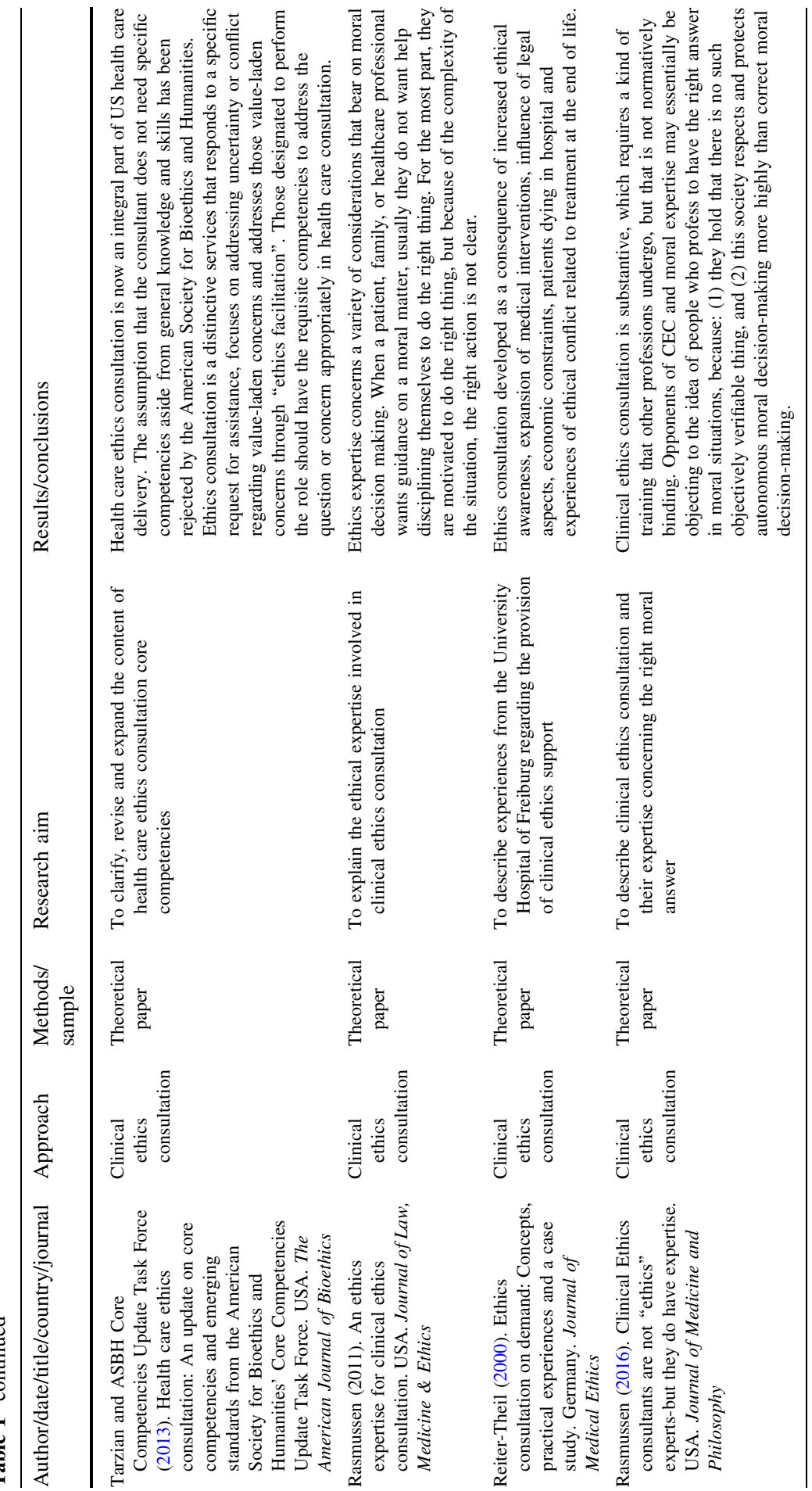




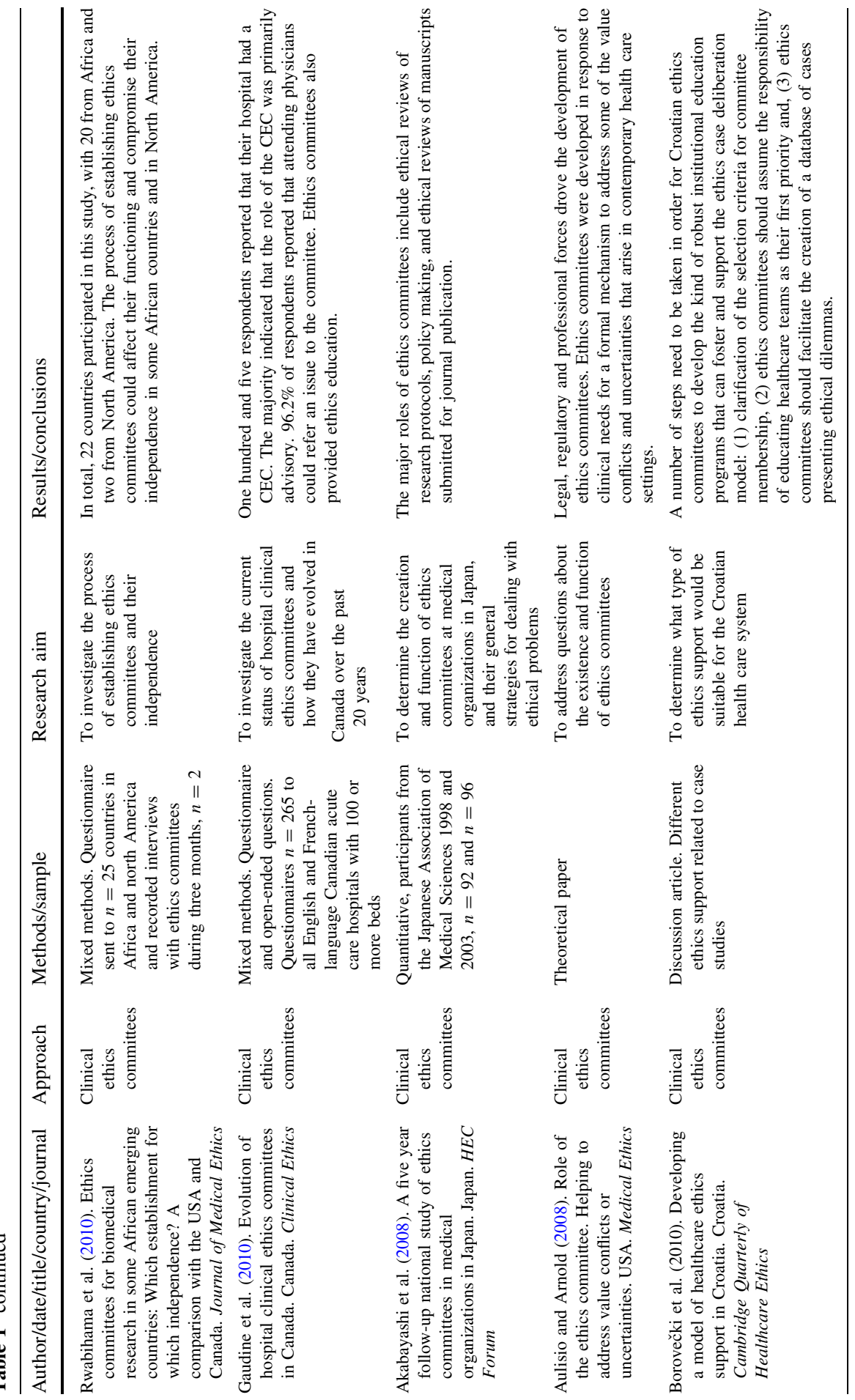




\begin{tabular}{|c|c|c|c|c|}
\hline 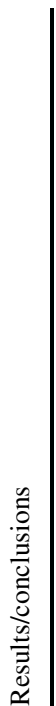 & 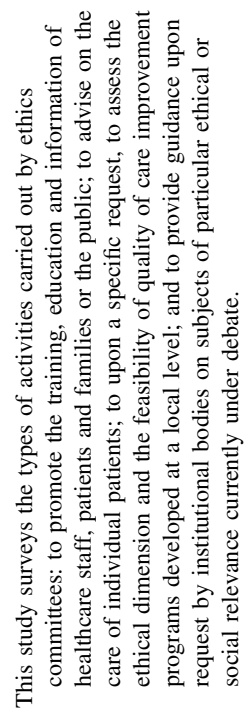 & 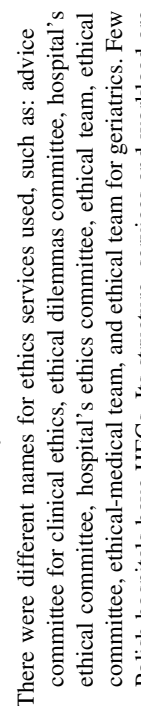 & 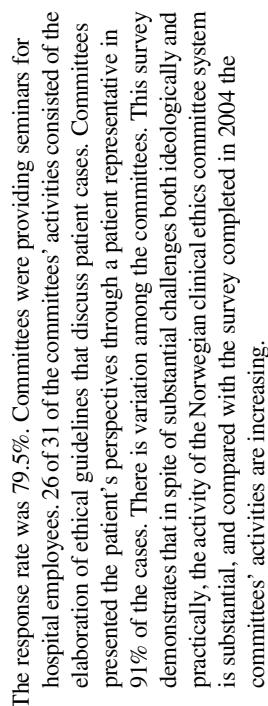 & 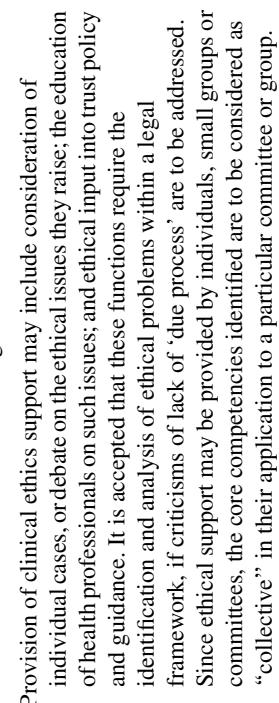 \\
\hline & 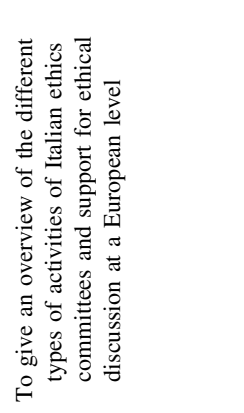 & 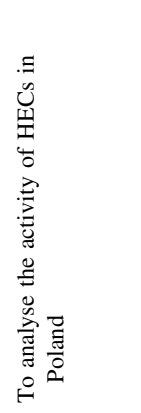 & 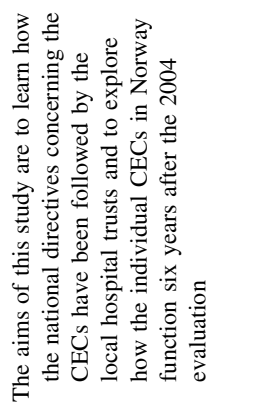 & 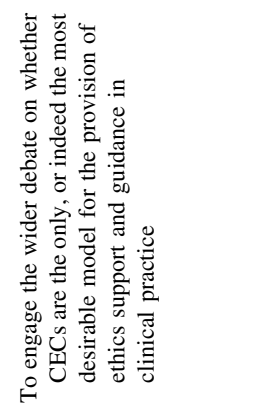 \\
\hline 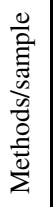 & 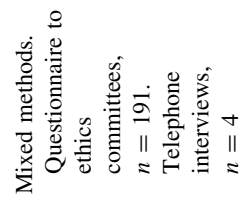 & 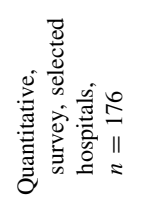 & 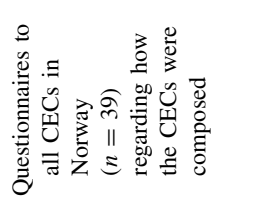 & 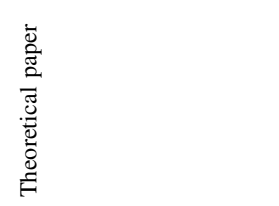 \\
\hline 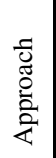 & 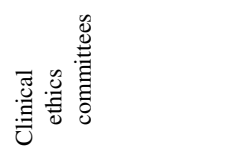 & 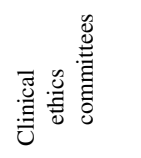 & 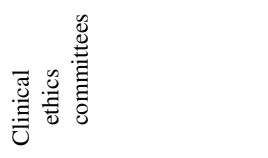 & 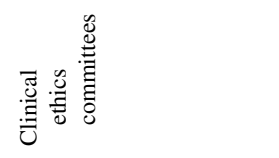 \\
\hline 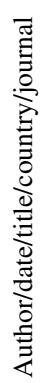 & 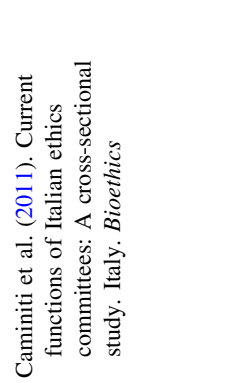 & 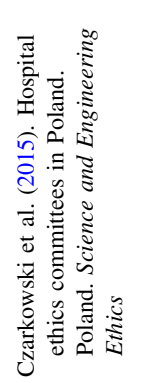 & 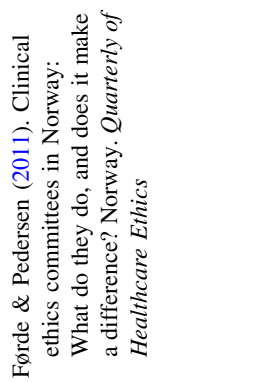 & 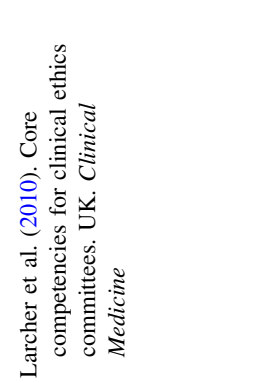 \\
\hline
\end{tabular}




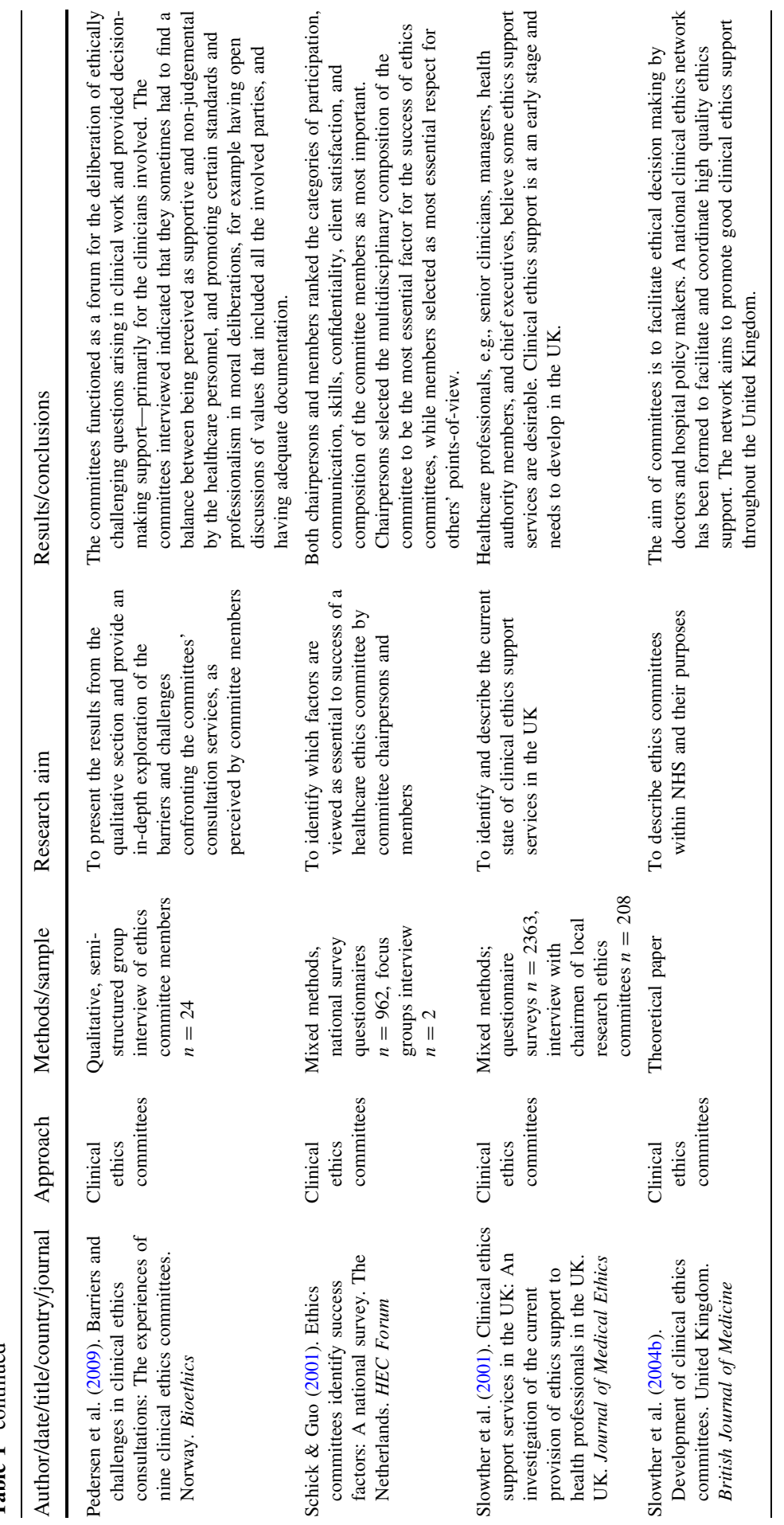




\begin{tabular}{|c|c|c|c|}
\hline & 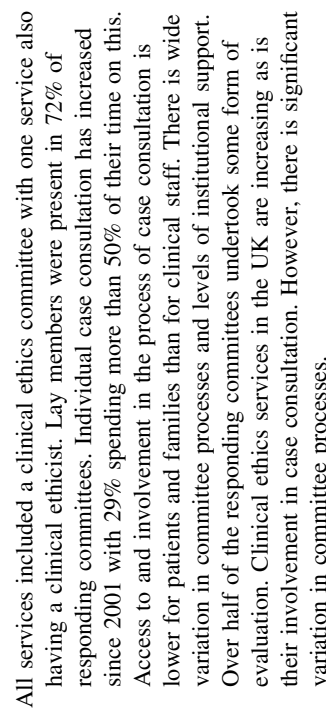 & 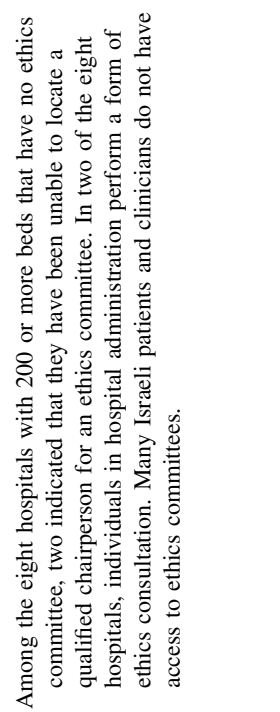 & 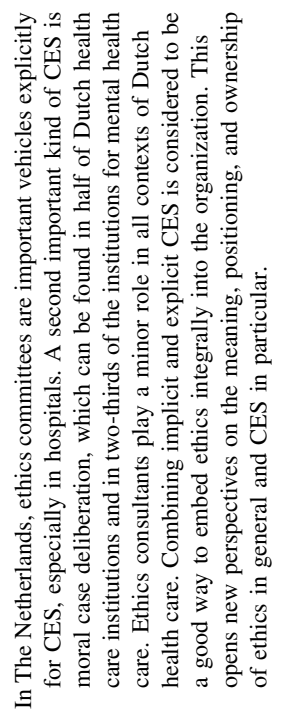 \\
\hline & 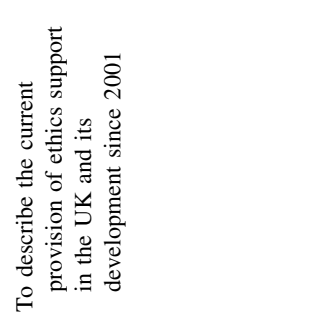 & 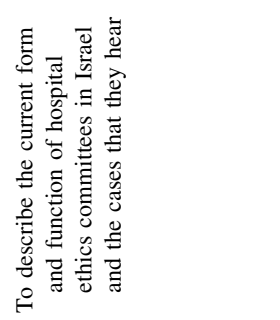 & 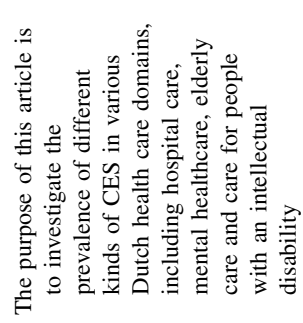 \\
\hline & 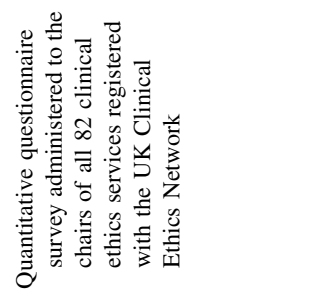 & 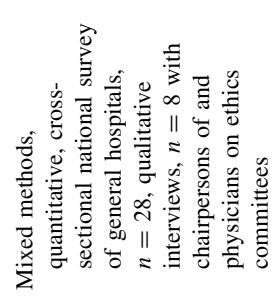 & 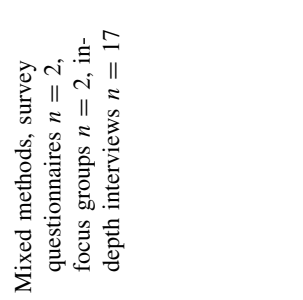 \\
\hline & 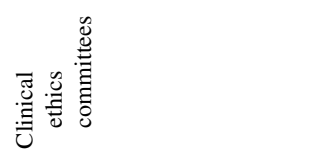 & 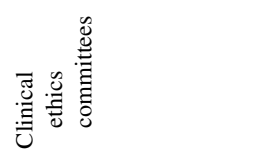 & 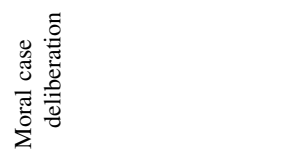 \\
\hline 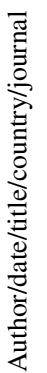 & 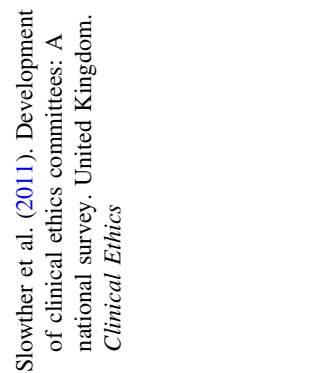 & 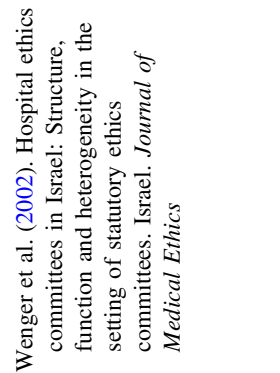 & 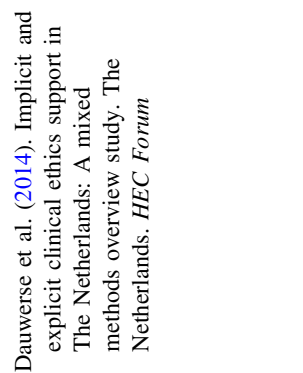 \\
\hline
\end{tabular}

\section{包 Springer}




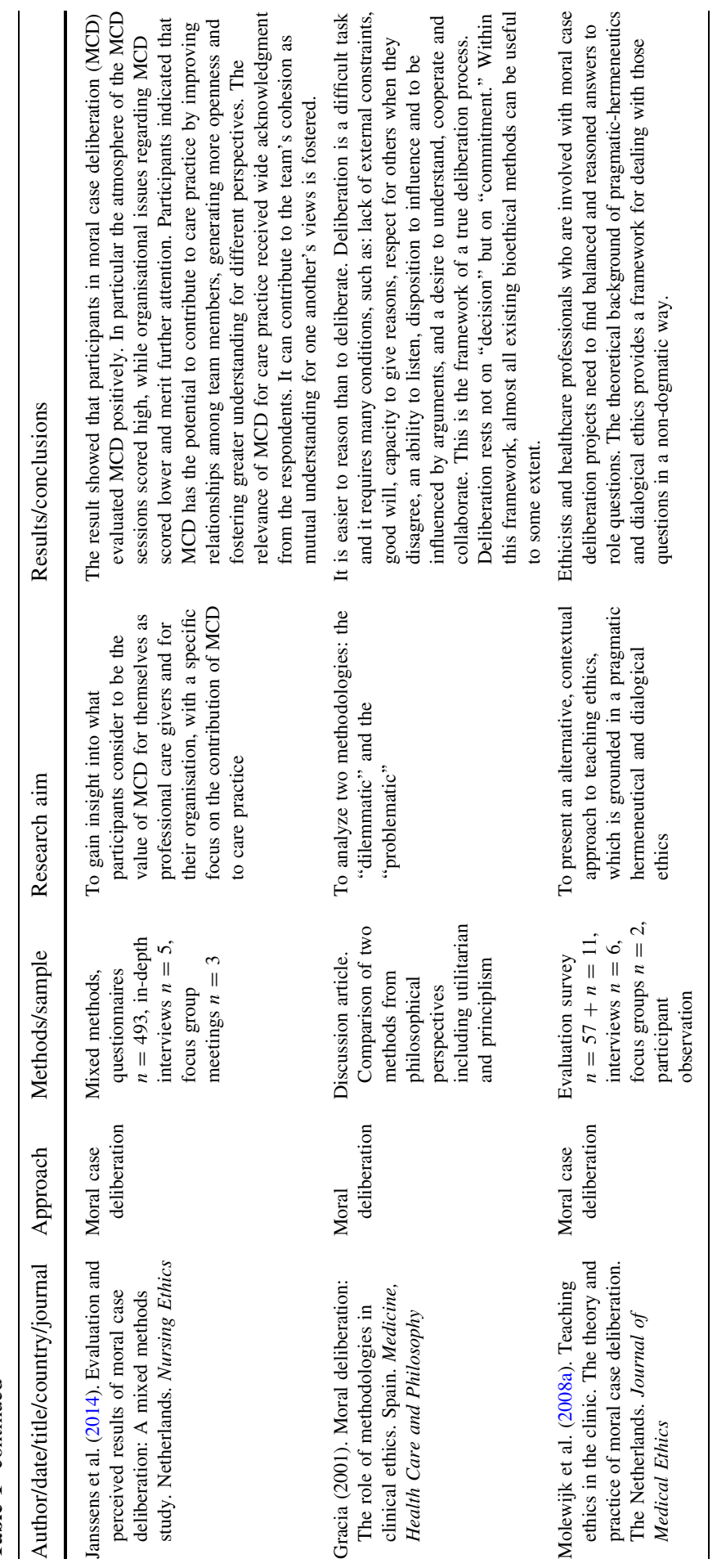




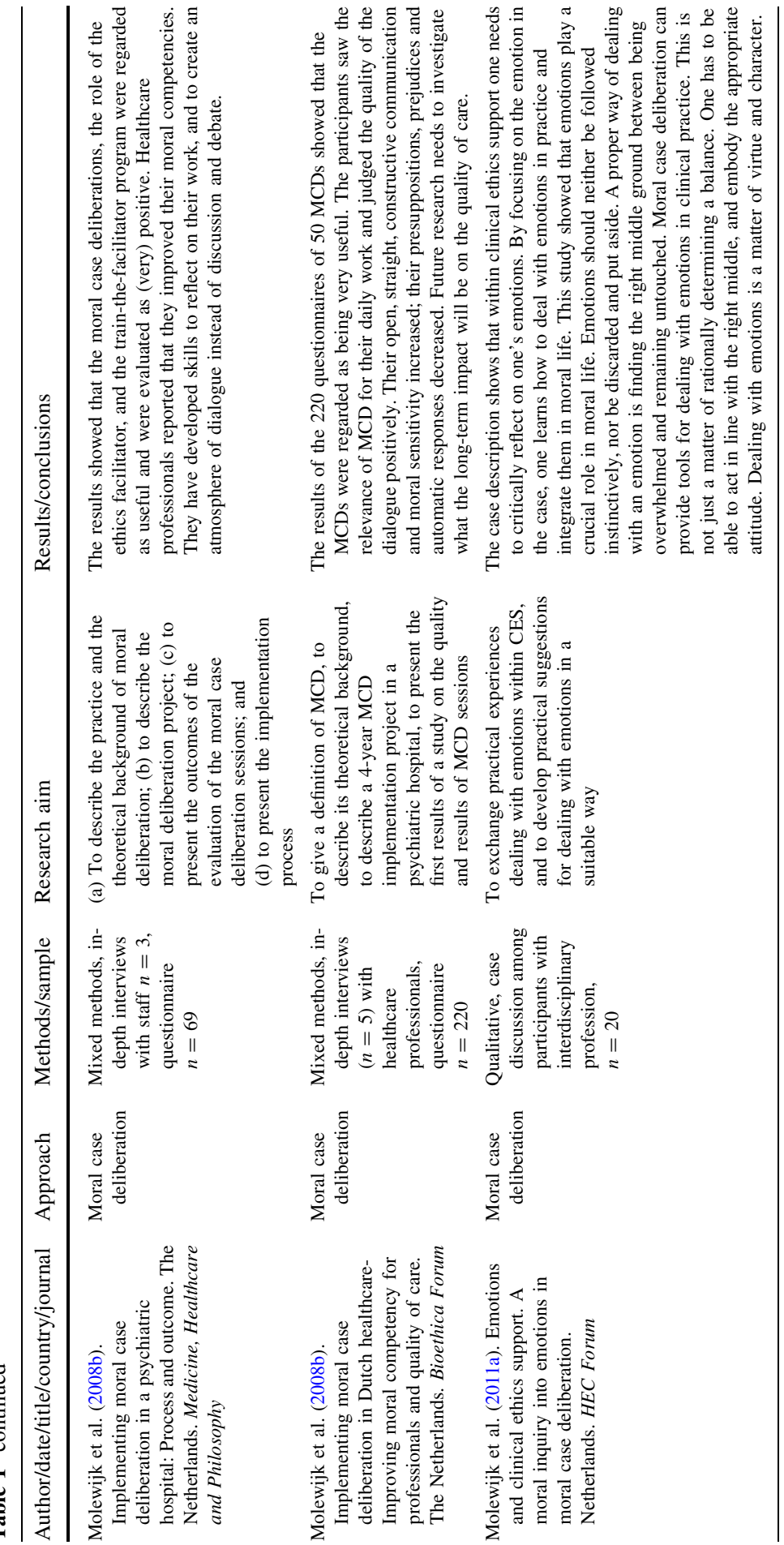




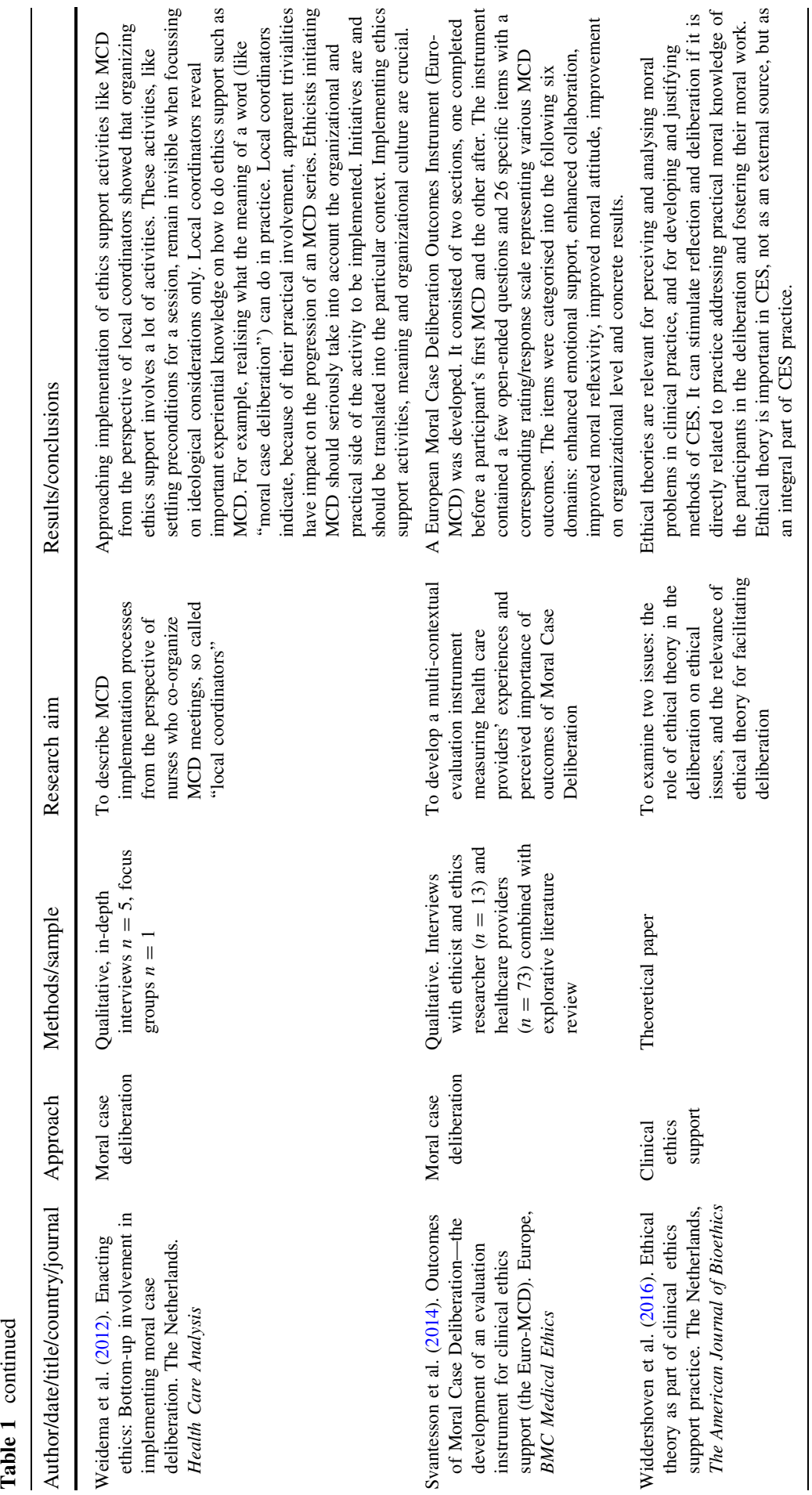




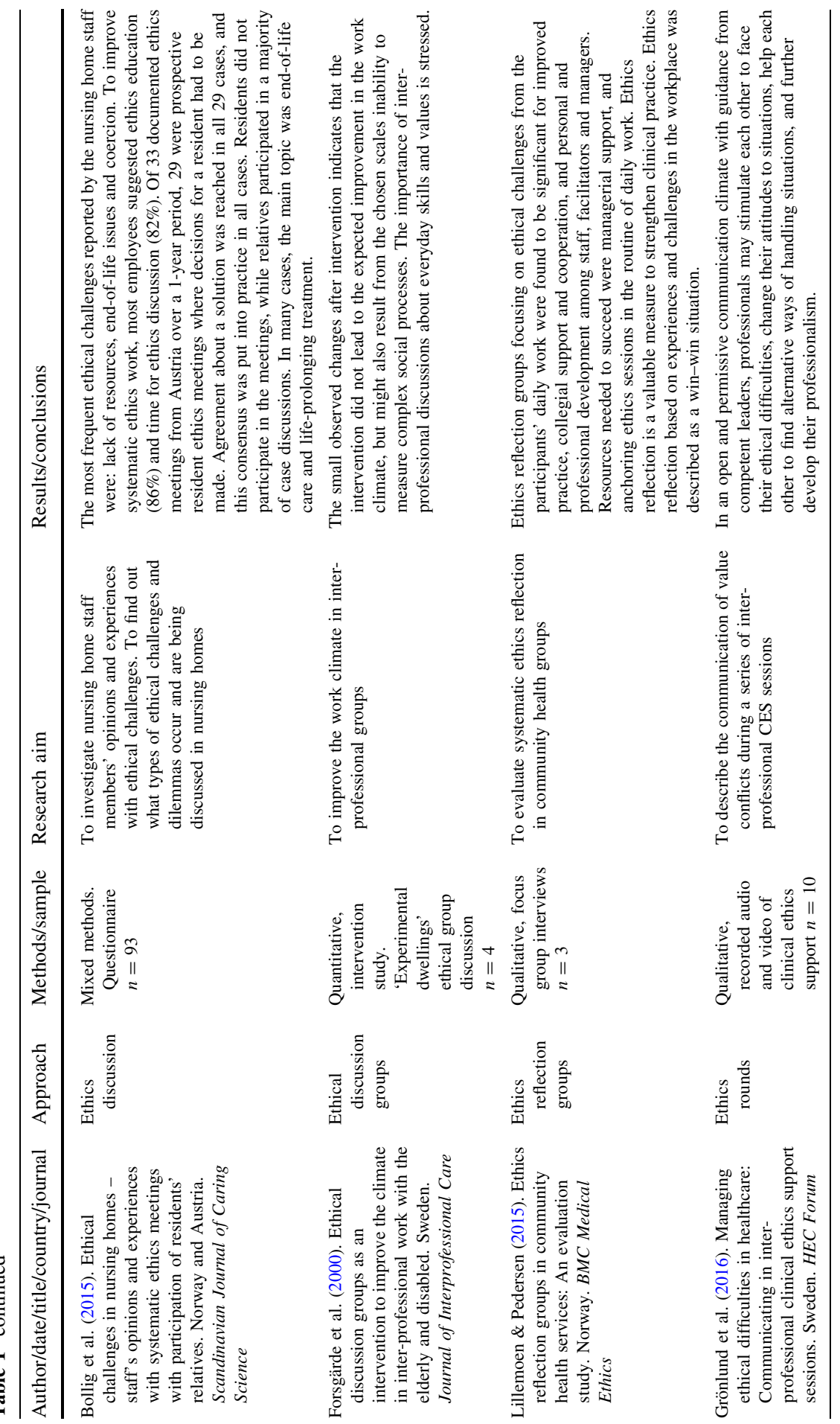




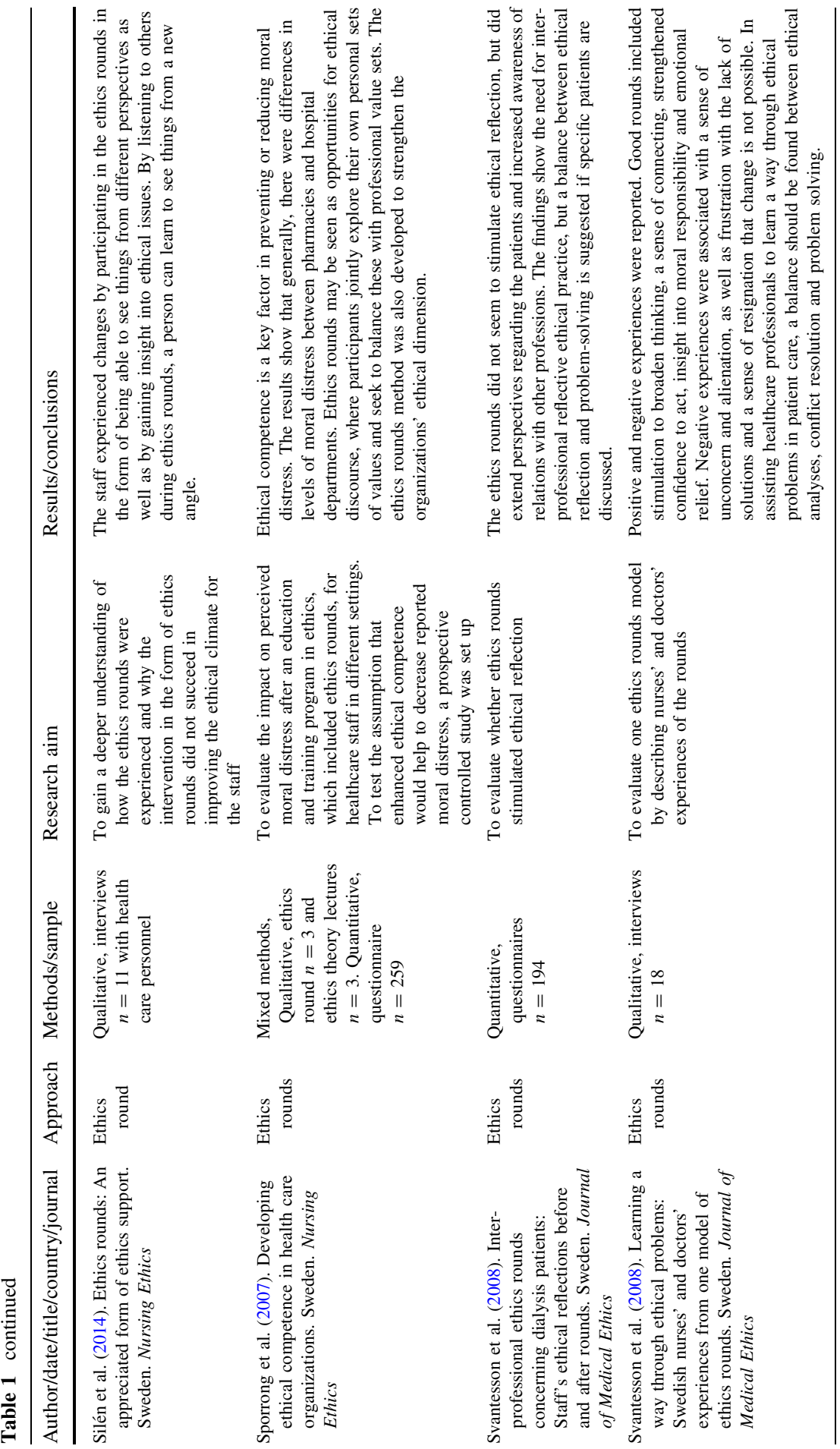




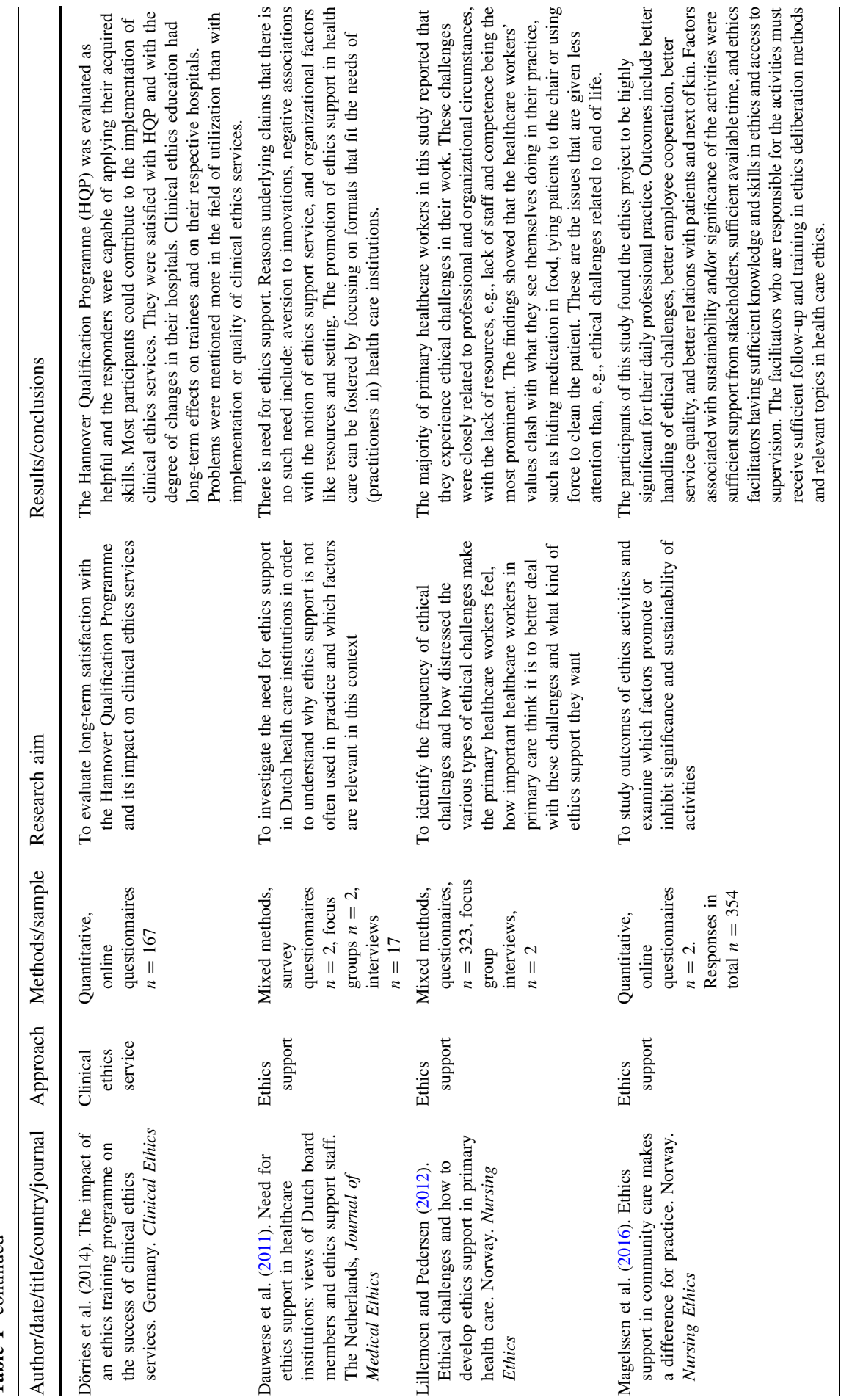




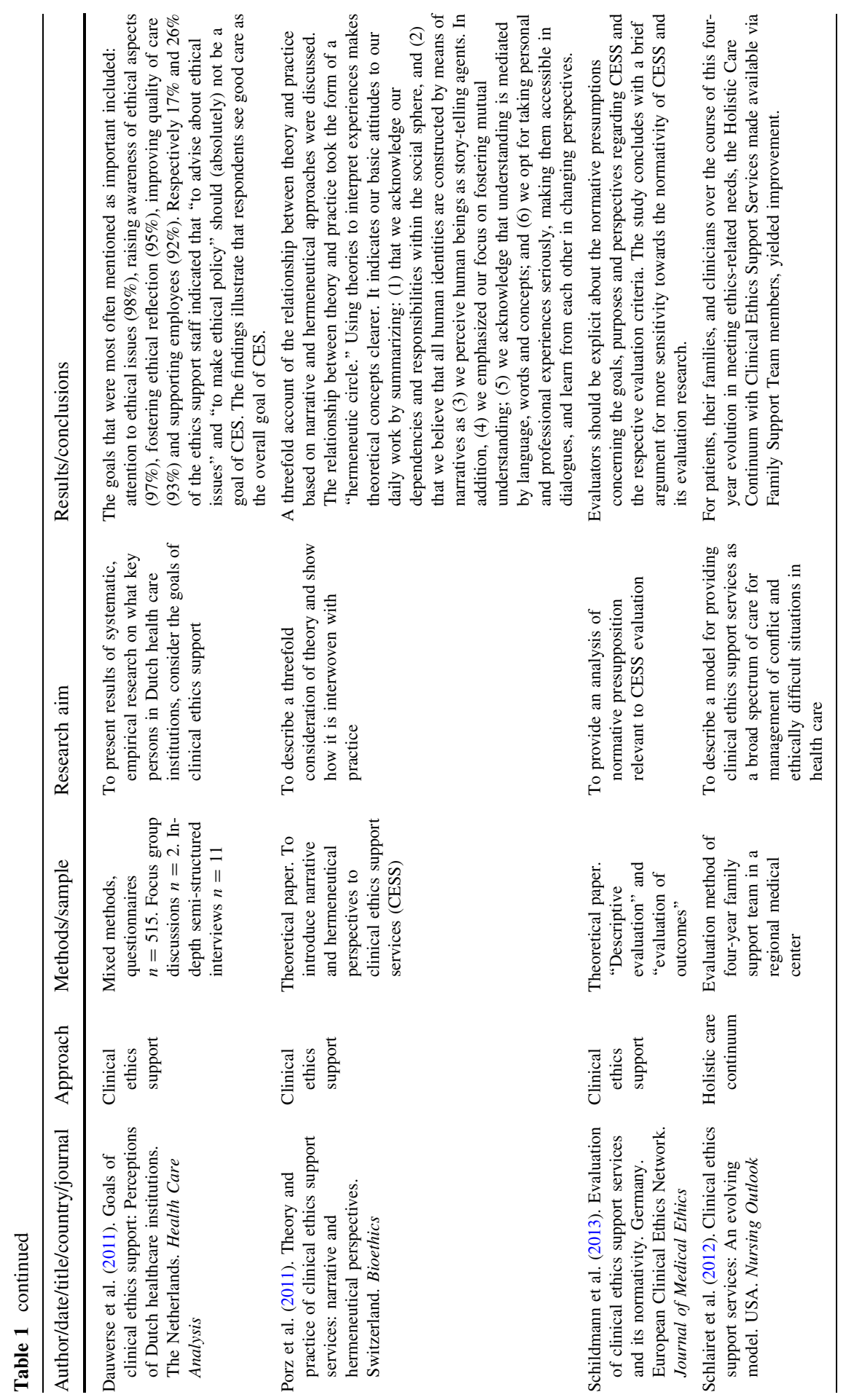




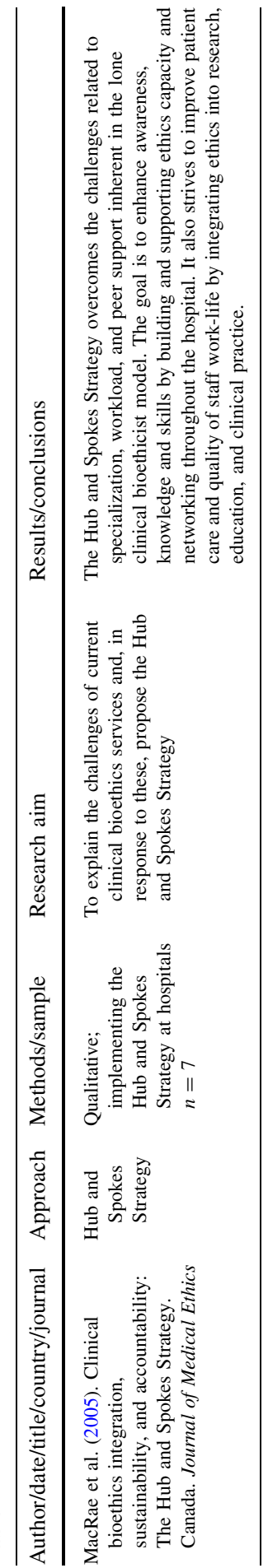

\section{Springer}


each category were synthesized into an integrated result. The integration is meant to synthesize and clarify what is known about a target phenomenon (Sandelowski et al. 2006), such as different approaches to CES.

\section{Results}

The results revealed four CES approaches that are available to support healthcare personnel who are dealing with ethical issues (Table 1). They comprised: clinical ethics consultation, clinical ethics committees, moral case deliberation, and ethics rounds/ethics discussion groups/ethics reflection groups, which we have combined together due to the similarity of their form and content. Although CES can be categorized into four main approaches, it is important to point out that due to a lack of firm definitions, it is difficult to draw distinct lines between them, which results in some overlap of the boundaries.

\section{Clinical Ethics Consultation}

Clinical ethics consultation is defined as a set of services that generally occurs following requests from healthcare personnel, patients or their surrogates (Aulisio et al. 2000). It can also be performed routinely by a permanent body such as a hospital ethics committee (Reiter-Theil 2000; Tomazic et al. 2004). The consultation is provided by an individual or a small team of individuals in response to ethical issues (Adams 2009; Aulisio et al. 2000; Tarzian and ASBH Core Competencies Update Task Force 2013). Those who provide consultations have various professions, such as physicians, nurses, social workers or members of the clergy (McClimans et al. 2016). It is argued that the person(s) who provide the consultations are required to have certain skills and competencies in ethics, in order to support healthcare personnel in dealing with ethical problems (Aulisio et al. 2000).

Ethics consultations have been shown to help patients and personnel clarify ethical problems arising in daily health care practices and to improve collaborative decision-making (Fox et al. 2007; Tarzian and ASBH Core Competencies Update Task Force 2013). Ethics consultations may have the goal of improving quality of care for the patient and/or for solving certain aspects of ethical conflicts that occur between healthcare personnel, patients and next-of-kin (Aulisio et al. 2000; Paola and Walker 2006).

Beside requests concerning specific patient cases, ethical consultation services can provide educational activities in order to increase awareness concerning ethics in the clinic (Fukuyama et al. 2008) or to help deal with moral distress (McClimans et al. 2016).

In the US, there has been a movement to certify ethics consultants to assure that they possess key knowledge and skill competencies (Tarzian and ASBH Core Competencies Update Task Force 2013). Ethics consultants should possess a range of knowledge competencies that includes moral reasoning and ethical theory, relevant ethical codes, health law and local policies, and knowledge regarding the 
clinical context and staff and patient perspectives (Tomazic et al. 2004). In terms of skills, ethics consultants should have the ability and interpersonal skills to assess the nature of the ethical conflict by drawing on relevant ethics knowledge and "process" skills required to conduct clinical ethics consultation services effectively. In addition, a code of ethics has been developed by the American Society for Bioethics and Humanities, which identifies a set of professional responsibilities for those engaged in healthcare ethics consultation (Tarzian et al. 2015).

Ethics consultation services are multifaceted. There is no agreement regarding their core role worldwide and they vary in role and function depending on the country. For example, in Japan, ethics consultation services may prioritize the review of scientific and clinical research (Fukuyama et al. 2008) before case analysis and patient consultation (Adams 2009; Aulisio et al. 2009; Tarzian and ASBH Core Competencies Update Task Force 2013). Ethical consultation services can be used in specific ways, such as in response to requests for assistance in addressing uncertainty or conflict regarding a value-laden conflict of interest (Aulisio et al. 2000; Paola and Walker 2006). This can be between various stakeholders, such as patients, next-of-kin, healthcare personnel or the health organization (Adams 2009; Tarzian and ASBH Core Competencies Update Task Force 2013). The role of ethical consultation may be less specific, such as when consultations are triggered by the institution in order to educate health personnel in how to deal with moral distress, to improve ethical and moral qualities of decisionmaking and actions (McClimans et al. 2016), or to review research protocols (Fukuyama et al. 2008). Some ethics consultant(s), (depending on the country) even have the authority to make decisions or give advice/recommendations, whether alone or in agreement with next-of-kin or healthcare staff, as to the best course of action.

The idea that an ethicist/consultant with specific knowledge can assume the role of ethics expert and make judgments in ethically difficult situations has been supported by some (Aulisio et al. 2000; Tarzian and ASBH Core Competencies Update Task Force 2013). It has been criticized by others, who argue that while there is expertise in ethics, there is no such thing as an ethics expert (Adams 2009; Rasmussen 2011, 2016). Regardless of the contrasting positions described above, the approach of ethics consultation remains authoritarian, because while the consultation process is triggered by health personnel requesting a consultation, it is the consultants who have the authority and power (as a result of their position) to interpret the clinical ethics case (Agich 2001).

\section{Clinical Ethics Committees}

A clinical ethics committee is typically a standing committee which functions as an independent institution or authority to provide a formal mechanism for dealing with ethical issues in clinical settings (Akabayashi et al. 2008; Aulisio and Arnold 2008). Generally, the members of clinical ethics committees have various professional backgrounds such as: bioethicists/ethics consultants, clergy, social workers, lawyers, nurses, physicians, psychologists, therapists and community representatives (Akabayashi et al. 2008; Schick and Guo 2001). The goals and responsibilities 
of the clinical ethics committee are to protect the rights, safety and well-being of the patient in the health care setting or human subjects in research projects (Borovecki et al. 2010; Gaudine et al. 2010; Slowther et al. 2011). In addition, they are to identify and analyze ethical issues in clinical practice (Larcher et al. 2010; Slowther et al. 2001), promote training and education of health personnel, and provide guidance upon request (Caminiti et al. 2011). They commonly respond to requests to address ethical issues related to ongoing as well as retrospective patient cases; identify ethical needs within clinical settings; support healthcare personnel, patients and next-of-kin (Førde and Pedersen 2011), find agreements and make decisions; and review research protocols (Fukuyama et al. 2008; Gaudine et al. 2010). Clinical ethics committees are involved in responding to ethical issues, such as informed consent to treatment (Borovecki et al. 2010; Caminiti et al. 2011). Sometimes they provide decision-making support (Pedersen et al. 2009) in end-of-life situations or the continuation of life support (Slowther et al. 2004b). Clinical ethics committees can also provide education, seminars, workshops and training in ethics for hospital employees (Borovecki et al. 2010; Caminiti et al. 2011; Pedersen et al. 2009). They can review research protocols (except in the United States, where separate committees deal with this process), provide ethical input into hospital policies (Pedersen et al. 2009) and create guidelines (Slowther et al. 2001). Additionally, they can give an "expert" opinion regarding issues, such as the provision of treatment against a patient's will and the disclosure of medical information against a patient's wishes when it might be deemed necessary (Wenger et al. 2002). Clinical ethics committees promote an ethical dimension to health care and generate possibilities for improvement in care quality (Caminiti et al. 2011; Czarkowski et al. 2015).

There is no formal legal or regulatory governing framework for clinical ethics committees, which is in contrast to research ethics committees worldwide (Larcher et al. 2010; Slowther et al. 2004b; Wenger et al. 2002). Clinical ethics committees vary in function, structure and goals worldwide, but there are some commonalities in terms of the provision of advice (Slowther et al. 2001) and recommendations concerning the best course of action or discussions that lead to a good decisionmaking process (Schick and Guo 2001; Slowther et al. 2004b). Some committees themselves assume the responsibility to develop and improve guidelines and policies regarding prospective ethical challenges in clinical practice, and others are mandated by the health care institutions to do so (Aulisio and Arnold 2008; Slowther et al. 2001). Clinical ethics committees seem to have formal authority and legitimacy (without generalizing) to provide advice and recommendations concerning ethical issues arising in healthcare institutions (Slowther et al. 2004b).

\section{Moral Case Deliberation}

The approach of Moral Case Deliberation (MCD) has been described in several ways. It is said to consist of a collaborative, systematic reflection on real clinical cases (Molewijk et al. 2008a, b; Weidema et al. 2012); methodological reflection on concrete cases among healthcare professionals; and facilitator-led collective dialogue (Gracia 2001) of healthcare personnel who reflect on a concrete moral 
question connected to real cases in their practice (Janssens et al. 2014; Molewijk et al. 2008a, b; Weidema et al. 2012). The goal of MCD is to support healthcare personnel to manage ethically difficult situations in their clinical practice (Svantesson et al. 2014), and to enhance ethical reflection among healthcare personnel concerning ethical issues and thus improve the quality of patient care. In other words, MCD can help deal with concrete problems and help train healthcare personnel so that they improve their ethical competencies. MCD is a "deliberationist" approach to ethical issues that supports the idea that reflection over ethically difficult situations is vital, and aims to make health personnel aware of ethical issues as well as related theories and how they might be applied in practice (Widdershoven et al. 2016). It supports health personnel in managing ethical issues and making independent decisions from the standpoint that health personnel are entitled to make decisions about how to deal with issues in clinical practice (Molewijk et al. 2008a, b).

During an MCD session, which can last from 45 minutes to one day and is led by an external facilitator, participants reflect individually and collectively about the moral aspects of a particular patient case (Molewijk et al. 2011a). The collective group discussion is facilitated by an ethicist or someone trained in some kind of conversation method relevant to ethics (Molewijk et al. 2008a, b; Svantesson et al. 2014; Weidema et al. 2012). MCD sessions are led by a facilitator who has no authority to decide on or to provide/recommend suggestions concerning the best course of action (Molewijk et al. 2008a, b; Weidema et al. 2012). The facilitator's main role is only to stimulate an ethical discussion (mutual reflection) and to illuminate the ethical aspects of the case (Dauwerse et al. 2014; Gracia 2001).

In an MCD session, health personnel take the initiative to discuss a patient's case that they have found ethically difficult to manage (Molewijk et al. 2008a, b; Molewijk et al. 2011a). Each person participates in the MCD on equal terms regardless of his or her job title and all voices are to be listened to and respected. During the MCD session different kinds of emotion, e.g., frustration, anger, sadness can be expressed (Molewijk et al. 2011a). MCD is similar in many ways to ethics rounds (described below), but it is distinctive because it uses theoretically based conversation methods (Janssens et al. 2014), such as the Dilemma method or Socratic Dialogue (Svantesson et al. 2014; Weidema et al. 2012). The Dilemma method has been used in the Netherlands with the goal of helping healthcare personnel seek consensus regarding ethical issues (Molewijk et al. 2008a, b, 2011a; Weidema et al. 2012). In contrast, Socratic Dialogue aims to help healthcare personnel develop ethical skills and a reflective attitude towards the ethical issues they experience in their everyday clinical practice (Molewijk et al. 2008a, b).

\section{Ethics Rounds/Ethics Discussion Groups/Ethics Reflection Groups}

These three approaches overlap with each other to some extent since they have commonalities in terms of how they are constructed as well as in their functions and goals.

Ethics rounds are a form of facilitator/ethicist-led reflection, which involves discussion of a particular patient's medical and ethical issues (Grönlund et al. 2016; 
Silén et al. 2014; Svantesson et al. 2008). During ethics rounds, healthcare personnel from different disciplines reflect over a patient's case that they are finding ethically difficult to resolve (MacRae et al. 2005; Svantesson et al. 2008), or over ethical challenges related to professional and organizational circumstances (Grönlund et al. 2016; Lillemoen and Pedersen 2012). The goal of the ethics round is to stimulate ethical reflection and promote mutual understanding between professional groups (MacRae et al. 2005; Silén et al. 2014), particularly through listening to each other's perspectives (Svantesson et al. 2008). Ethics rounds have been described as supporting healthcare personnel develop ethical competencies and gain insight into ethical issues (Silén et al. 2014; Sporrong et al. 2007). They help healthcare personnel to examine their own views and obtain a better awareness and understanding of their colleagues' ways of thinking and acting (Grönlund et al. 2016; Sporrong et al. 2007).

Other kinds of ethics support alongside ethics rounds are ethics discussion groups and ethics reflection groups, which have been used by healthcare personnel in nursing homes to discuss issues regarding end-of-life care, lack of resources and coercion (Bollig et al. 2015; Lillemoen and Pedersen 2012). Ethics discussion groups have also been used to improve the work climate and job satisfaction among nursing staff (Forsgärde et al. 2000), while ethics reflection groups have been described as an approach in which healthcare personnel sit together and reflect over ethical challenges in their daily practice (Lillemoen and Pedersen 2015). Other related kinds of ethics support have been used to train and educate healthcare personnel to acquire skills needed to respond to ethical issues (Dörries et al. 2010; MacRae et al. 2005). Promotion of ethics support in health care can be fostered by focusing on the needs of the healthcare institution and using ethical theory to interpret the experiences of the healthcare personnel's everyday work (Dauwerse et al. 2011; Porz et al. 2011). Ethics support facilitated by a person with knowledge in ethics has been shown to help staff handle ethical challenges, improve cooperation between employees (Magelssen et al. 2016), increase healthcare personnel's awareness of ethical aspects, and improve relations between staff and patients/next-of-kin (Magelssen et al. 2016; Schlairet et al. 2012). To ensure that ethics support is improving the quality of care, evaluation is essential (Schildmann et al. 2013).

These approaches to ethics support are all characterized by the involvement of inter-professional healthcare teams in collective group discussions to encourage reflection over ethical issues that occur in clinical practice from the perspectives of the healthcare personnel themselves (Schlairet et al. 2012). A bioethicist or facilitator has the role of creating an equal atmosphere for everyone during the ethics rounds/discussion (MacRae et al. 2005). It is common that the bioethicist/facilitator receives some information concerning the case in advance, or asks the participants to prepare a case or an ethical issue to reflect over (Grönlund et al. 2016). The bioethicist/facilitator has no authority and does not act as an expert in ethics, nor do they provide advice about what to do, but only stimulates group discussion (Magelssen et al. 2016; Silén et al. 2014). One fundamental idea with these kinds of discussions is that the personnel may stimulate each other, enhance critical thinking (Svantesson et al. 2008), or change their attitudes regarding the 
situations. These discussions have the goal of helping personnel deal with moral distress (Sporrong et al. 2007), getting them to help each other and to cooperate in order to find alternative ways of handling situations, and to ultimately improve the quality of patient care (Dauwerse et al. 2011; Janssens et al. 2014). In these types of ethics support, healthcare personnel are considered to be qualified (Dörries et al. 2010) and legitimate decision-makers in regard to ethically difficult situations. Ultimately, making decisions or reaching a consensus regarding the best course of action in a particular case remains with the healthcare personnel (Silén et al. 2014; Sporrong et al. 2007).

\section{Discussion}

The included articles $(n=54)$ covered a range of clinical ethics support. The study aim was to describe which clinical ethics support approaches are available to support healthcare personnel in clinical practice in terms of their construction, functions and goals. The existing literature clearly demonstrates the increased worldwide interest for clinical ethics support.

There are similarities and differences among the established approaches. In the first approach, clinical ethics consultation, the ethicist assists the healthcare personnel with patient cases where there could be issues regarding patient autonomy, informed consent, confidentiality, and surrogate decision making (Aulisio et al. 1998, 2000). Ethics consultation can sometimes be recognized as having an authoritarian "top-down" perspective (Adams 2013; Agich 1995; Aulisio et al. 1998), especially if the outcomes of the consultation are not beneficial for the patient or the healthcare personnel. Here the consultant has an influential advisory role and may propose solutions, or act as the primary ethical decision maker with respect to the outcome and the process (Aulisio et al. 2000; La Puma and Schiedermayer 1991).

The second approach utilizes clinical ethics committees; it has many similarities to clinical ethics consultation. In this approach, instead of an individual person with expertise in ethics, a group of "experts" assists healthcare personnel by providing advice or recommendations from an "expert" point-of-view (Dauwerse 2013; Hoffman 1991). Traditionally, both clinical ethics consultation and clinical ethics committees have focused on providing advice or recommendations to healthcare personnel in clinical practice (Cranford and Doudera 1984). In addition, clinical ethics committees have been involved in supporting patients and their next-of-kin. Sometimes patient representatives are included in ethics committees (Førde and Pedersen 2011) when discussing patient cases. However, there seems to be variation in function and role regarding ethics support in ethics consultation and ethics committees both between countries and even within them. There is still no clear universal consensus of what ethics consultation should or should not provide during a case consultation.

In a third approach to CES, MCD is sometimes described as a "bottom-up" approach, in which reflection starts from the healthcare personnel's experiences of everyday ethical issues related to clinical practice (Molewijk et al. 2008a, b; 
Spijkerboer et al. 2016). This approach seeks to increase the healthcare personnel's insight into their moral responsibility (Svantesson et al. 2008) and to broaden perspectives through reflection. MCD differs from clinical ethics consultation and clinical ethics committees in that it fosters dialogue on ethical questions and reflection on ethical dilemmas (Dauwerse 2013; Stolper et al. 2014) rather than on decision-making in ethically difficult situations. The reflection in MCD is usually guided by a facilitator (Molewijk et al. 2011a), who is trained in various conversation methods, e.g., the Dilemma method and Socratic Dialogue (Molewijk et al. 2008a, b; Plantinga et al. 2012). The facilitator in the MCD does not claim be an "expert" in ethics, but merely stimulates healthcare personnel by asking questions about the case like Socrates did in his time (Stolper et al. 2014).

Finally, there are ethics rounds/ethics discussion groups/ethics reflection groups that are closely related to each other in how they are facilitated and the content they discuss. For this reason, we have chosen to discuss all three together as one approach. This fourth approach is also closely related to MCD. In a previous study, MCD was used as an umbrella term for ethics rounds/ethics discussion groups and ethics reflection groups (Svantesson et al. 2014). Previous studies described the group reflections as being positively regarded by healthcare personnel (van der Dam et al. 2011, 2013; Verkerk et al. 2004). It was said to increase their awareness concerning ethically difficult situations they experience in their clinical practice (Lillemoen and Pedersen 2015). It also increased job satisfaction and was associated with lower burnout rates, while workplaces without reflection remained unchanged.

Reflection is the act of sharing experiences and narratives in which the person is receptive for personal development. It has also been described as a process of learning and representation (Moon 2013). A reflective conversation for healthcare personnel in practice is fundamental in order to provide quality services (Schon 2003). The primary purpose of reflection is not to solve an issue arising in everyday practice, but to increase awareness of the various aspects of the issue. A positive side-effect of reflection could be that it leads to the ability to solve an issue that occurs. Reflection supports the idea of an enhanced critical thinking process. According to Dewey (1933), the purpose of reflection is to process knowledge in order to get a deeper understanding of a phenomenon. In health care, the personnel reflect on ethically difficult situations in order to learn more of what it means to act or not act in a certain way. Therefore, clinical ethics support in the form of reflection is vital for personnel working in health care settings. Personnel benefit from approaches that can create an atmosphere where they can have the freedom to express their feelings and emotions related to a case they are struggling with (Molewijk et al. 2011b).

Clinical ethics support from a "bottom-up" perspective might give healthcare professionals opportunities to think and reflect on issues they are facing in their everyday work. A dominant "top-down" perspective could be a less risky approach if, and only if, it removes ethical responsibility from the healthcare personnel (Agich 1995; Hansson 2002). For example, if a consultant makes a decision, or gives advice or a recommendation that is not beneficial for either the patient or the personnel, but only beneficial from an economical perspective. If later on the consequences of that decision or advice/recommendation proved detrimental to the 
patient, the healthcare personnel involved could free themselves from guilt by placing the blame on the consultant. If a decision or recommendation was based on a "bottom-up" approach that involves the reflections of the healthcare personnel, they would need to assume greater ethical responsibility and perhaps wish to reflect more in such situations. Consequently, the status of a professional "expert" in ethics might lead to a risk, an undermining, or a challenge to the healthcare personnel's personal autonomy, e.g., a limitation on their autonomy when dealing with ethical issues. According to Schon (2003), professional practitioners are specialists that encounter certain types of situations again and again in their daily work. They learn what to look for and how to respond to those particular types of situations (Schon 2003). Even though many ethically difficult situations are unique, repeating patterns can be found. Therefore, the ethical responsibility and choice of what to do should remain with the healthcare personnel in clinical practice (Hansson 2002). To permit someone from the outside to make a decision or give a recommendation in a particular situation could be risky (Hansson 2002).

\section{Strengths and Limitations}

A strength of this study is that the conclusions are based on literature that allowed an analysis of the established clinical ethics support approaches worldwide. In this integrative review, both qualitative and quantitative studies as well as theoretical papers were included. An integrated review allows the inclusion of several methodologies and can take into account a broader range of studies to develop a more comprehensive understanding of a phenomenon (Whittemore and Knafl 2005). Another strength is that we have searched data systematically with Mesh terms as well as manually. There are limitations as well. It was difficult to decide which articles to exclude since there are no real definitions as to what clinical ethics consultation really is. We included articles that described a clinical ethics support approach empirically, or theoretical papers that discussed an established approach. It was difficult to decide where to draw the line between approaches aimed only at supporting healthcare personnel with ethically difficult situations and approaches that support healthcare personnel as well as patients and next-of-kin. For example, some clinical ethics committees do support the patients and their next-of-kin, while other clinical ethics committees do not involve patients and next-of-kin in their annual meetings or when considering different situations. Even though there are similarities in the "top-down" perspective of the clinical ethics consultation and clinical ethics committees, it does not mean they are similar worldwide. Clinical ethics consultation and clinical ethics committees in different countries can differ in their role and function as well. In addition, in this review we considered only English-language papers and it is possible that other methods of ethics support have been developed in other language cultures. Future studies need to focus on defining and characterizing what clinical ethics support actually is, how it should function and if it should function differently in different countries; and if so, what are the possible reasons since many of the ethical issues are similar globally. Lastly, an additional interesting avenue for future research would be to perform a large-scale 
study of what types of ethical support practitioners are receiving, if they are satisfied with it and their perceptions regarding any effects on patient outcomes.

\section{Conclusions and Implications}

Clinical ethics support in the form of reflection is an important approach in order to deal with ethical challenges in health care settings. Traditionally, clinical ethics committees and ethics consultations have been the two approaches that are sometimes recognized (without generalizing) as having a focus on providing suggestions or recommendations to healthcare personnel from an expert point-ofview, and often with a basis in different medical principles or theories. Moral Case Deliberation (MCD) and ethics rounds/ethics discussion groups/ethics reflection groups seem to focus on fostering dialogue on ethical questions and ethical inquiries that are brought up by the healthcare personnel. It has been argued that approaches based on reflection may generate insight (Moon 2013). In MCD for example, reflection from a "bottom-up" perspective may support healthcare personnel to process their own thoughts and feelings. This might further help them become aware of other aspects they were previously unaware of in ethically difficult situations and how to deal with them in clinical practice. MCD is an explicit form of clinical ethics support that gives professionals support to improve their moral reflection skills (Dauwerse et al. 2014). Reflection in groups might in the long-term help healthcare personnel discover their own way of dealing with ethically difficult situations in order to act in the best interest of the patient.

To summarize, clinical ethics support from a "bottom-up" perspective might provide healthcare personnel with opportunities to think and reflect more than from a "top-down" perspective. While a "bottom-up" approach leaves healthcare personnel with the moral responsibility for their choice of action in clinical practice, a "top-down" approach risks removing that responsibility.

Acknowledgements We thank Örebro University and Stiftelsen Olle Engkvist Byggmästare for financial support (Grant Number CF 71-485/2008).

\section{Compliance with Ethical Standards}

Conflict of interest The authors declare that there are no conflicts of interest.

Open Access This article is distributed under the terms of the Creative Commons Attribution 4.0 International License (http://creativecommons.org/licenses/by/4.0/), which permits unrestricted use, distribution, and reproduction in any medium, provided you give appropriate credit to the original author(s) and the source, provide a link to the Creative Commons license, and indicate if changes were made.

\section{References}

Adams, D. M. (2009). Ethics consultation and "facilitated" consensus. Journal of Clinical Ethics, 20(1), 44-55.

Adams, D. M. (2013). Ethics expertise and moral authority: Is there a difference? The American Journal of Bioethics, 13(2), 27-28. doi:10.1080/15265161.2012.750391. 
Agich, G. J. (1995). Authority in ethics consultation. The Journal of Law, Medicine \& Ethics, 23(3), 273-283.

Agich, G. J. (2001). The question of method in ethics consultation. The American Journal of Bioethics, 1(4), 31-41. doi:10.1162/152651601317139360.

Akabayashi, A., Slingsby, B. T., Nagao, N., Kai, I., \& Sato, H. (2008). A five year follow-up national study of ethics committees in medical organizations in Japan. HEC Forum, 20(1), 49-60. doi:10. 1007/s10730-008-9059-4.

Åstrom, G., Furåker, C., \& Norberg, A. (1995). Nurses' skills in managing ethically difficult care situations: Interpretation of nurses'narratives. Journal of Advanced Nursing, 21(6), 1073-1080. doi:10.1046/j.1365-2648.1995.21061073.x.

Aulisio, M. P., \& Arnold, R. M. (2008). Role of the ethics committee: Helping to address value conflicts or uncertainties. CHEST Journal, 134(2), 417-424.

Aulisio, M. P., Arnold, R. M., \& Youngner, S. J. (1998). Can there be educational and training standards for those conducting health care ethics consultation? In J. F. Monagle \& D. C. Thomasma (Eds.), Health care ethics: Critical issues for the 21st century (pp. 484-496). Boston: Jones \& Bartlett Publishers.

Aulisio, M. P., Arnold, R. M., \& Youngner, S. J. (2000). Health care ethics consultation: Nature, goals, and competencies: A position paper from the society for health and human values-society for bioethics consultation task force on standards for bioethics consultation. Annals of Internal Medicine, 133(1), 59-69. doi:10.7326/0003-4819-133-1-200007040-00012.

Aulisio, M. P., Moore, J., Blanchard, M., Bailey, M., \& Smith, D. (2009). Clinical ethics consultation and ethics integration in an urban public hospital. Cambridge Quarterly of Healthcare Ethics, 18(4), 371-383.

Bartholdson, C., Lützén, K., Blomgren, K., \& Pergert, P. (2015). Experiences of ethical issues when caring for children with cancer. Cancer Nursing, 38(2), 125-132.

Beauchamp, T. L., \& Childress, J. F. (2009). Principles of biomedical ethics (7th ed.). Oxford: Oxford University Press.

Bollig, G., Schmidt, G., Rosland, J. H., \& Heller, A. (2015). Ethical challenges in nursing homes-Staff's opinions and experiences with systematic ethics meetings with participation of residents' relatives. Scandinavian Journal of Caring Sciences, 29(4), 810-823. doi:10.1111/scs.12213.

Borovecki, A., Makar-Ausperger, K., Francetić, I., Babić-Bosnac, S., Gordijn, B., Steinkamp, N., et al. (2010). Developing a model of healthcare ethics support in Croatia. Cambridge Quarterly of Healthcare Ethics, 19(3), 395-401. doi:10.1017/S0963180110000174.

Caminiti, C., Diodati, F., Gatti, A., Santachiara, S., \& Spinsanti, S. (2011). Current functions of Italian ethics committees: A cross-sectional study. Bioethics, 25(4), 220-227. doi:10.1111/j.1467-8519. 2009.01769.x.

Cassel, C. K. (1984). Deciding to forego life-sustaining treatment: Implications for policy in 1985 symposium. Cardozo Law Review, 6, 287-302.

Cohen, J., \& Erickson, J. (2006). Ethical dilemmas and moral distress in oncology nursing practice. Clinical Journal of Oncology Nursing, 10(6), 775-783. doi:10.1188/06.CJON.775-780.

Cranford, R. E., \& Doudera, A. E. (1984). The emergence of institutional ethics committees. Law, Medicine and Health Care, 12, 13-20.

Crigger, B. J. (1995). Negotiating the moral order: Paradoxes of ethics consultation. Kennedy Institute of Ethics Journal, 5(2), 89-112.

Czarkowski, M., Kaczmarczyk, K., \& Szymańska, B. (2015). Hospital ethics committees in Poland. Science and Engineering Ethics, 21(6), 1525-1535.

Dauwerse, L. (2013). Moving ethics state of the art of clinical ethics support in the Netherlands. Vianen: Proefschriftmaken.

Dauwerse, L., Abma, T. A., Molewijk, B., \& Widdershoven, G. (2011). Need for ethics support in healthcare institutions: Views of Dutch board members and ethics support staff. Journal of Medical Ethics, 37(8), 456-460. doi:10.1136/jme.2010.040626.

Dauwerse, L., Weidema, F., Abma, T., Molewijk, B., \& Widdershoven, G. (2014). Implicit and explicit clinical ethics support in The Netherlands: A mixed methods overview study. HEC Forum, 26(2), 95-109. doi:10.1007/s10730-013-9224-2.

Dewey, J. (1933). How we think: A restatement of the relation of reflective thinking to the educative process. Boston: D.C. Heath \& Company.

Doran, E., Fleming, J., Kerridge, I., \& Steward, C. (2015). Clinical ethics support: Literature review. Sydney: Ministry of Health. 
Dörries, A., Simon, A., Neitzke, G., \& Vollmann, J. (2010). Implementing clinical ethics in German hospitals: Content, didactics and evaluation of a nationwide postgraduate training programme. Journal of Medical Ethics, 36(12), 721-726.

Førde, R., \& Pedersen, R. (2011). Clinical ethics committees in Norway: What do they do, and does it make a difference? Cambridge Quarterly of Healthcare Ethics, 20(3), 389-395. doi:10.1017/ S0963180111000077.

Forsgärde, M., Westman, B., \& Nygren, L. (2000). Ethical discussion groups as an intervention to improve the climate in interprofessional work with the elderly and disabled. Journal of Interprofessional Care, 14(4), 351-361. doi:10.1080/13561820020003900.

Fox, E., Myers, S., \& Pearlman, R. A. (2007). Ethics consultation in United States hospitals: A national survey. The American Journal of Bioethics, 7(2), 13-25. doi:10.1080/15265160601109085.

Fukuyama, M., Asai, A., Itai, K., \& Bito, S. (2008). A report on small team clinical ethics consultation programmes in Japan. Journal of Medical Ethics, 34(12), 858-862. doi:10.1136/jme.2008.024307.

Garrard, J. (2010). Health sciences literature review made easy: The matrix method (3rd ed.). Sudbury, MA: Jones \& Bartlett Learning, USA.

Gaudine, A., Thorne, L., LeFort, S. M., \& Lamb, M. (2010). Evolution of hospital clinical ethics committees in Canada. Journal of Medical Ethics, 36(3), 132-137.

Gracia, D. (2001). Moral deliberation: The role of methodologies in clinical ethics. Medicine, Health Care and Philosophy, 4(2), 223-232.

Graneheim, U. H., \& Lundman, B. (2004). Qualitative content analysis in nursing research: Concepts, procedures and measures to achieve trustworthiness. Nurse Education Today, 24(2), 105-112.

Grönlund, C. F., Dahlqvist, V., Zingmark, K., Sandlund, M., \& Söderberg, A. (2016). Managing ethical difficulties in healthcare: Communicating in inter-professional clinical ethics support sessions. HEC Forum, 28(4), 321-338.

Hansson, M. G. (2002). Imaginative ethics-Bringing ethical praxis into sharper relief. Medicine, Health Care and Philosophy, 5(1), 33-42. doi:10.1023/A:1014257603144.

Hermsen, M., \& van der Donk, M. (2009). Nurses' moral problems in dialysis. Nursing Ethics, 16(2), 184-191. doi:10.1177/0969733008100078.

Hoffman, D. E. (1991). Regulating ethics committees in health care institutions-Is it time? Maryland Law Review, 50(3), 746-797.

Janssens, R. M., van Zadelhoff, E., van Loo, G., Widdershoven, G., \& Molewijk, B. (2014). Evaluation and perceived results of moral case deliberation: A mixed methods study. Nursing Ethics. doi:10. $1177 / 0969733014557115$.

Kälvemark, S., Höglund, A. T., Hansson, M. G., Westerholm, P., \& Arnetz, B. (2004). Living with conflicts-ethical dilemmas and moral distress in the health care system. Social Science and Medicine, 58(6), 1075-1084. doi:10.1016/S0277-9536(03)00279-X.

Karlsson, M., Karlsson, C., Barbosa da Silva, A., Berggren, I., \& Söderlund, M. (2013). Community nurses' experiences of ethical problems in end-of-life care in the patient's own home. Scandinavian Journal of Caring Sciences, 27(4), 831-838. doi:10.1111/j.1471-6712.2012.01087.x.

La Puma, J., \& Schiedermayer, D. L. (1991). Ethics consultation: Skills, roles, and training. Annals of Internal Medicine, 114(2), 155-160.

Larcher, V., Slowther, A., \& Watson, A. R. (2010). Core competencies for clinical ethics committees. Clinical Medicine, 10(1), 30-33. doi:10.7861/clinmedicine.10-1-30.

Lillemoen, L., \& Pedersen, R. (2012). Ethical challenges and how to develop ethics support in primary health care. Nursing ethics, 20(1), 96-108.

Lillemoen, L., \& Pedersen, R. (2015). Ethics reflection groups in community health services: An evaluation study. BMC Medical Ethics, 16(25). doi:10.1186/s12910-015-0017-9.

Lindseth, A., Marhaug, V., Norberg, A., \& Uden, G. (1994). Registered nurses' and physicians' reflections on their narratives about ethically difficult care episodes. Journal of Advanced Nursing, 20(2), 245-250. doi:10.1046/j.1365-2648.1994.20020245.x.

MacRae, S., Chidwick, P., Berry, S., Secker, B., Hébert, P., Shaul, R. Z., et al. (2005). Clinical bioethics integration, sustainability, and accountability: The Hub and Spokes Strategy. Journal of Medical Ethics, 31(5), 256-261. doi:10.1136/jme.2003.007641.

Magelssen, M., Gjerberg, E., Lillemoen, L., Førde, R., \& Pedersen, R. (2016). Ethics support in community care makes a difference for practice. Nursing Ethics. doi:10.1177/0969733016667774.

McClimans, L., Pressgrove, G., \& Rhea, J. (2016). A qualitative study of US clinical ethics services: Objectives and outcomes. Narrative Inquiry in Bioethics, 6(2), 127-142. doi:10.1353/nib.2016. 0019. 
Molewijk, B., Abma, T. A., Stolper, M., \& Widdershoven, G. (2008a). Teaching ethics in the clinic. The theory and practice of moral case deliberation. Journal of Medical Ethics, 34(2), 120-124. doi:10. 1136/jme.2006.018580.

Molewijk, B., Kleinlugtenbelt, D., Pugh, S. M., \& Widdershoven, G. (2011a). Emotions and clinical ethics support. A moral inquiry into emotions in moral case deliberation. HEC Forum, 23(4), 257-268. doi:10.1007/s10730-011-9162-9.

Molewijk, B., Kleinlugtenbelt, D., \& Widdershoven, G. (2011b). The role of emotions in moral case deliberation: Theory, practice, and methodology. Bioethics, 25(7), 383-393. doi:10.1111/j.14678519.2011.01914.x.

Molewijk, B., van Zadelhoff, E., Lendemeijer, B., \& Widdershoven, G. (2008b). Implementing moral case deliberation in Dutch healthcare; Improving moral competency of professionals and the quality of care. Bioethica Forum, 1(1), 57-65.

Moon, J. A. (2013). Reflection in learning and professional development: Theory and practice. New York: Routledge.

Oberle, K., \& Hughes, D. (2001). Doctors' and nurses' perceptions of ethical problems in end-of-life decisions. Journal of Advanced Nursing, 33(6), 707-715. doi:10.1046/j.1365-2648.2001.01710.x.

Owen, J.W. (2001). Clinical ethics support in the UK: A review of the current position and likely development. http://www.nuffieldtrust.org.uk/sites/files/nuffield/publication/Clinical_Ethics_ Support\%20March\%202001.pdf.

Paola, F. A., \& Walker, R. (2006). Ethicians, ethicists and the goals of clinical ethics consultation. Internal and Emergency Medicine, 1(1), 5-14. doi:10.1007/BF02934714.

Pauly, B., Varcoe, C., Storch, J., \& Newton, L. (2009). Registered nurses' perceptions of moral distress and ethical climate. Nursing Ethics, 16(5), 561-573. doi:10.1177/0969733009106649.

Pedersen, R., Akre, V., \& Førde, R. (2009). Barriers and challenges in clinical ethics consultations: The experiences of nine clinical ethics committees. Bioethics, 23(8), 460-469. doi:10.1111/j.1467-8519. 2008.00664.x.

Plantinga, M., Molewijk, B., de Bree, M., Moraal, M., Verkerk, M., \& Widdershoven, G. (2012). Training healthcare professionals as moral case deliberation facilitators: Evaluation of a Dutch training programme. Journal of Medical Ethics, 38(10), 630-635. doi:10.1136/medethics-2012-100546.

Porz, R., Landeweer, E., \& Widdershoven, G. (2011). Theory and practice of clinical ethics support services: Narrative and hermeneutical perspectives. Bioethics, 25(7), 354-360. doi:10.1111/j.14678519.2011.01911.x.

Puntillo, K. A., Benner, P., Drought, T., Drew, B., Stotts, N., Stannard, D., et al. (2001). End-of-life issues in intensive care units: A national random survey of nurses' knowledge and beliefs. American Journal of Critical Care, 10(4), 216-229.

Rasmussen, L. M. (2011). An ethics expertise for clinical ethics consultation. Journal of Law, Medicine \& Ethics, 39(4), 649-661. doi:10.1111/j.1748-720X.2011.00632.x.

Rasmussen, L. M. (2016). Clinical ethics consultants are not "ethics" experts-But they do have expertise. Journal of Medicine and Philosophy, 41(4), 384-400. doi:10.1093/jmp/jhw012.

Rasoal, D., Kihlgren, A., James, I., \& Svantesson, M. (2015). What healthcare teams find ethically difficult: Captured in 70 moral case deliberations. Nursing Ethics, 23(8), 825-837. doi:10.1177/ 0969733015583928.

Reiter-Theil, S. (2000). Ethics consultation on demand: Concepts, practical experiences and a case study. Journal of Medical Ethics, 26(3), 198-203.

Reiter-Theil, S., \& Hiddeman, W. (2000). Is there a need for clinical ethics support services? Medicine, Health Care and Philosophy: A European Journal, 3(3), 370.

Rwabihama, J. P., Girre, C., \& Duguet, A. M. (2010). Ethics committees for biomedical research in some African emerging countries: Which establishment for which independence? A comparison with the USA and Canada. Journal of Medical Ethics, 36(4), 243-249.

Sandelowski, M., Voils, C. I., \& Barroso, J. (2006). Defining and designing mixed research synthesis studies. Research in the Schools: A Nationally Refereed Journal Sponsored by the Mid-South Educational Research Association and the University of Alabama, 13(1), 29.

SBU. (2014). Swedish agency for health technology assessment and assessment of social services. (Utvärdering av Metoder i Hälso- och Sjukvården: En handbok). http://www.sbu.se/globalassets/ ebm/metodbok/sbushandbok.pdf.

Schaffer, M. A. (2007). Ethical problems in end-of-life decisions for elderly Norwegians. Nursing Ethics, $14(2), 242-257$. 
Schick, I. C., \& Guo, L. (2001). Ethics committees identify success factors: A national survey. HEC Forum, 13(4), 344-360.

Schildmann, J., Molewijk, B., Benaroyo, L., Forde, R., \& Neitzke, G. (2013). Evaluation of clinical ethics support services and its normativity. Journal of Medical Ethics, 39(11), 681-685. doi:10.1136/ medethics-2012-100697.

Schlairet, M. C., Kiser, K., \& Norris, S. (2012). Clinical ethics support services: An evolving model. Nursing Outlook, 60(5), 309-315. doi:10.1016/j.outlook.2012.01.002.

Schochow, M., Schnell, D., \& Steger, F. (2015). Implementation of clinical ethics consultation in German hospitals. Science and Engineering Ethics. doi:10.1007/s11948-015-9709-2.

Schon, D. A. (2003). The reflective practitioner: How professionals think in action. London: Ashgate Publishing Ltd.

Silén, M., Ramklint, M., Hansson, M. G., \& Haglund, K. (2014). Ethics rounds: An appreciated form of ethics support. Nursing Ethics. doi:10.1177/0969733014560930.

Silén, M., Svantesson, M., \& Ahlström, G. (2008). Nurses' conceptions of decision making concerning life-sustaining treatment. Nursing Ethics, 15(2), 160-173. doi:10.1177/0969733007086014.

Slettebø, A., \& Bunch, H. E. (2004). Ethics in nursing homes: Experience and casuistry. International Journal of Nursing Practice, 10, 159-165.

Slowther, A., Bunch, C., Woolnough, B., \& Hope, T. (2001). Clinical ethics support services in the UK: An investigation of the current provision of ethics support to health professionals in the UK. Journal of Medical Ethics, 27(suppl 1), i2-i8. doi:10.1136/jme.27.suppl_1.i2.

Slowther, A., Johnston, C., Goodall, J., \& Hope, T. (2004a). A practical guide for clinical ethics support. Oxford: The Ethox Centre, University of Oxford.

Slowther, A., Johnston, C., Goodall, J., \& Hope, T. (2004b). Development of clinical ethics committees. BMJ, 328(7445), 950-952. doi:10.1136/bmj.328.7445.950.

Slowther, A., McClimans, L., \& Price, C. (2011). Development of clinical ethics services in the UK: A national survey. Journal of Medical Ethics. doi:10.1136/medethics-2011-100173.

Sørlie, V., Lindseth, A., Udén, G., \& Norberg, A. (2000). Women physicians' narratives about being in ethically difficult care situations in paediatrics. Nursing Ethics, 7(1), 47-62. doi:10.1177/ 096973300000700107.

Spijkerboer, R. P., van der Stel, J. C., Widdershoven, G., \& Molewijk, B. (2016). Does moral case deliberation help professionals care for the homeless in dealing with their dilemmas? A mixedmethods responsive study. HEC Forum. doi:10.1007/s10730-016-9310-3.

Sporrong, S. K., Arnetz, B., Hansson, M. G., Westerholm, P., \& Höglund, A. T. (2007). Developing ethical competence in health care organizations. Nursing Ethics, 14(6), 825-837. doi:10.1177/ 0969733007082142.

Stolper, M., Molewijk, B., \& Widdershoven, G. (2014). Learning by doing. Training health care professionals to become facilitator of moral case deliberation. HEC Forum, 27(1), 47-59. doi:10. 1007/s10730-014-9251-7.

Svantesson, M., Anderzén-Carlsson, A., Thorsén, H., Kallenberg, K., \& Ahlström, G. (2008a). Interprofessional ethics rounds concerning dialysis patients: Staff's ethical reflections before and after rounds. Journal of Medical Ethics, 34(5), 407-413. doi:10.1136/jme.2007.023572.

Svantesson, M., Karlsson, J., Boitte, P., Schildman, J., Dauwerse, L., Widdershoven, G., et al. (2014). Outcomes of moral case deliberation-The development of an evaluation instrument for clinical ethics support (the Euro-MCD). BMC Medical Ethics, 15, 30. doi:10.1186/1472-6939-15-30.

Svantesson, M., Löfmark, R., Thorsén, H., Kallenberg, K., \& Ahlström, G. (2008b). Learning a way through ethical problems: Swedish nurses' and doctors' experiences from one model of ethics rounds. Journal of Medical Ethics, 34(5), 399-406. doi:10.1136/jme.2006.019810.

Tabitha, M., Powledge, M. S., \& Fletcher, J. (1979). Guidelines for the ethical, social and legal issues in prenatal diagnosis-A report from the Genetics Research Group of the Hastings Center. Institute of Society, Ethics and the Life Sciences, 300, 168-172. doi:10.1056/NEJM197901253000404.

Tarzian, A., \& ASBH Core Competencies Update Task Force. (2013). Health care ethics consultation: An update on core competencies and emerging standards from the American Society for Bioethics and Humanities' Core Competencies Update Task Force. American Journal of Bioethics, 13(2), 3-13. doi:10.1080/15265161.2012.750388.

Tarzian, A., Wocial, L. D., \& ASBH Core Competencies Update Task Force Committee. (2015). A code of ethics for health care ethics consultants: Journey to the present and implications for the field. The American Journal of Bioethics, 15(5), 38-51. doi:10.1080/15265161.2015.1021966. 
Tomazic, T., Anderson, E., Badro, V., \& Katz, B. (2004). Clinical ethics consultation. ASA Social Statistics Section, 2046-2048.

Ulrich, C. M., Taylor, C., Soeken, K., O’Donnell, P., Farrar, A., Danis, M., et al. (2010). Everyday ethics: Ethical issues and stress in nursing practice. Journal of Advanced Nursing, 66(11), 2510-2519. doi:10.1111/j.1365-2648.2010.05425.x.

van der Dam, S., Abma, T. A., Molewijk, B., Kardol, M. J. M. T., Schols, M. G. A. J., \& Widdershoven, G. (2011). Organizing moral case deliberation experiences in two Dutch nursing homes. Nursing Ethics, 18(3), 327-340. doi:10.1177/0969733011400299.

van der Dam, S., van der Schols, M. G. A. J., Kardol, M. J. M. T., Molewijk, B., Widdershoven, G., \& Abma, T. A. (2013). The discovery of deliberation. From ambiguity to appreciation through the learning process of doing moral case deliberation in Dutch elderly care. Social Science and Medicine, 83, 125-132. doi:10.1016/j.socscimed.2013.01.024.

Verkerk, M., Lindemann, H., Maeckelberghe, E., Feenstra, E., Hartoungh, R., \& de Bree, M. (2004). Enhancing reflection: An interpersonal exercise in ethics education. Hastings Center Report, 34(6), 31-38. doi: $10.2307 / 3528175$.

Weidema, F., Molewijk, B., Widdershoven, G., \& Abma, T. A. (2012). Enacting ethics: Bottom-up involvement in implementing moral case deliberation. Health Care Analysis, 20(1), 1-19. doi:10. 1007/s10728-010-0165-5.

Wenger, N. S., Golan, O., Shalev, C., \& Glick, S. (2002). Hospital ethics committees in Israel: Structure, function and heterogeneity in the setting of statutory ethics committees. Journal of Medical Ethics, 28(3), 177-182. doi:10.1136/jme.28.3.177.

Whittemore, R., \& Knafl, K. (2005). The integrative review: Updated methodology. Journal of Advanced Nursing, 52(5), 546-553. doi:10.1111/j.1365-2648.2005.03621.x.

Widdershoven, G., Metselaar, S., \& Molewijk, B. (2016). Ethical theory as part of clinical ethics support practice. American Journal of Bioethics, 16(9), 34-36. doi:10.1080/15265161.2016.1196260. 